\title{
La participación de eclesiásticos castellanos en las empresas bélicas de la regencia y del reinado de Fernando I de Aragón*
}

\author{
Participation of Castilian Clergy in the Military Campaigns of the \\ Regency and Reign of Fernando I of Aragón
}

\author{
SANTIAGo GonZÁlez SÁncheZ**
}

\begin{abstract}
RESUMEN
El presente artículo, aunque se centra en las figuras de tres dignatarios eclesiásticos castellanos y su actuación concreta en dos importantes hechos de armas, las campañas granadinas del infante don Fernando en 1407 y 1410, y el asedio y conquista de Balaguer ya como rey de Aragón en 1413, transciende esos momentos concretos, pues indaga en la trayectoria anterior y posterior de esos prelados y su vinculación con el infante-rey, para intentar explicar el protagonismo que tuvieron en esos hechos. Por otro lado, es una muestra más de la estrecha relación entre el poder político y el eclesiástico y de la importante ayuda castellana con que el rey de Aragón siempre contó.
\end{abstract}

\begin{abstract}
This article deals primarily with three ecclesiastical dignitaries and their specific role in two important military battles: the infante Fernando's Granada campaign of 1407 and 1410, as well as the siege and conquest of Balaguer as king of Aragon in 1413. Furthermore, it examines the career of these clergymen both before and after their relation with the «infante»-king in order to apprehend the exact role they had in these events. Additionally, this study demonstrates the tight relationship between the political and ecclesiastical powers and the importance of the continuous Castilian support given to the king of Aragon.
\end{abstract}

* Fecha de recepción del artículo: 2013-10-20. Fecha de aceptación del artículo: 2014-01-26.

Las abreviaturas utilizadas son las siguientes: ACA., Archivo de la Corona de Aragón; ACB., Archivo Capitular de Barcelona; ACPa., Archivo Capitular de Palencia; ADM., Archivo Ducal de Medinaceli; AGS., Archivo General de Simancas; AMPa., Archivo Municipal de Palencia; Arm. Armario; BNP., Bibilioteca Nacional de París; BZ., Biblioteca Zabálburu; carp. carpeta; Col. Colección; DHEE., Diccionario de Historia Eclesiástica de España; fol. folio; leg. legajo; Ms. Esp. Manuscrito España; n.ำ número; perg. pergamino; pp. páginas; r recto; RAH., Real Academia de la Historia; reg. registro; v vuelto; vol. volumen.

" Doctor en Historia Medieval por la Universidad Complutense de Madrid. C.e.: santitrifo@gmail.com 


\section{PALABRAS CLAVE KEY WORDS}

Obispos, campañas militares, Fernando I, Castilla, Corona de Aragón, siglo XV.
Bishops, Military Campaigns, Fernando I, Castile, Crown of Aragón, Fifteenth century.

\section{SUMARIO}

1. El contexto: la regencia en Castilla y el reinado en Aragón.-2. Las campañas granadinas de 1407 de 1410.-3. El asedio a Balaguer, 1413.-4. Breve semblanza biográfica de los obispos: Sancho de Rojas, Alfonso de Argüello y Diego Gómez de Fuensalida.-5. Pagos ordenados por el obispo de Zamora en relación con el asedio a Balaguer.-6 Conclusión. Apéndice.

\section{EL CONTEXTO: LA REGENCIA DE CASTILLA Y EL REINADO DE ARAGÓN}

La situación de Castilla a la muerte de Enrique III y la minoría de edad de su sucesor Juan II están lejos de la imagen idílica que transmiten las crónicas. La realidad fue muy distinta pues a los problemas heredados se sumaron otros como el de la sucesión, por lo que el nuevo reinado surgía lleno de tremendas incertidumbres, como la derivada de la postura de los estamentos privilegiados ante una nueva minoría de edad. En tal sentido, el real o supuesto ofrecimiento de la corona al infante don Fernando por un grupo de nobles, sería un elemento distorsionador más, aparte del problema de la custodia del monarca, pues no solo se dilucidaba quién controlaría el poder de Castilla en años sucesivos sino, y quizá más importante, qué forma de entender la monarquía existente en la época acabaría imponiéndose.

A los anteriores hay que añadir la imposición de una regencia compartida, por razones tan diversas como el distinto carácter de los corregentes, y poco después por la división de las provincias del reino entre la reina doña Catalina y el infante don Fernando, que llevó aparejada la de ciertas instituciones de la administración. Esta medida temporal se extendió hasta la muerte de don Fernando y revela su influencia, pues trataba de salvaguardar su patrimonio, la herencia de sus hijos y de asegurar la empresa guerrera. Sin embargo, la división administrativa también conllevó la de prelados y nobles entre uno y otro de los regentes, y en ocasiones dificultó el normal funcionamiento de algunas instituciones.

El control del poder por el infante y la práctica anulación de su corregente tuvo que ver con el peligro para el primero de ver truncados sus planes bélicos sobre el reino de Granada y políticos de control del Consejo Real. Se iniciaba así un ascenso personal y familiar incontestable, de lo que algunas muestras son: la campaña militar que culminó con la toma de Antequera, el conseguir sendos maes- 
trazgos para dos de sus hijos, el acuerdo matrimonial para su primogénito con la hermana del rey de Castilla, o la precedencia sobre su sobrino al trono de la Corona de Aragón.

Las campañas militares contra el reino de Granada en 1407 y en 1410 son, entre otros ejemplos, buena muestra del afianzamiento del infante en el poder, como acertaron a ver algunos de sus detractores contemporáneos.

Sus éxitos militares y su experiencia política fueron, sin duda, una buena carta de presentación para su más alta ambición: el trono de la Corona de Aragón; lo que en buena medida condicionó la política castellana durante los dos años de interregno. Su reivindicación se caracteriza por su firmeza y la utilización de todos los medios disponibles a su alcance e influencias para lograrlo, primero en Castilla y después en los distintos territorios de la Corona de Aragón.

Su nombramiento como rey trascendía los límites de los territorios a él sujetos y su época y se inserta en un complejo panorama interno y externo, en el que algunos de sus objetivos eran acabar con el Cisma de la Iglesia, salvaguardar el patrimonio regio, afianzar la presencia comercial de sus nuevos súbditos en el Mediterráneo y consolidarse en el trono.

En este último caso, don Fernando supuso una ruptura con la tradición pues, aunque descendía por línea materna de la casa real de Aragón, era castellano de nacimiento y de pensamiento. La oposición a su elección, personalizada en el conde de Urgel y extendida a ciertos individuos y grupos de población, fue la amenaza más grave a la que tuvo que hacer frente. Su experiencia militar, los vínculos vasalláticos que tenía con nobles castellanos y de sus nuevos reinos, la competencia de sus colaboradores, los errores de su adversario y de sus fieles, así como las presiones que ejerció y las ayudas que recibió facilitaron su triunfo en Balaguer y la prisión del conde don Jaime de Urgel, tras lo cual pudo consolidarse en el trono, después de año y medio, aproximadamente, de reinado.

Don Fernando desarrolló una amplia red diplomática. Sus numerosos proyectos, frustados o inacabados por su brevedad en el trono, le obligaron a implicarse en la política peninsular y continental, actuando sobre él como acicate los éxitos de otros reyes del ámbito hispano, la preocupación por su descendencia o su deseo de fama y renombre 1 .

Todos esos problemas unidos a sus intereses en Castilla tuvieron mucho que ver con la importante presencia de colaboradores castellanos a su lado en Aragón, en que ésta fuese continua y en que se extendiese a todas las áreas de gobierno y a todos los territorios. Aquí se estudian las acciones y las figuras de tres eclesiásticos castellanos que tuvieron un papel relevante en varias de sus empresas guerreras, tanto en su época como regente como en su periodo como monarca. Por un

1 La figura del monarca la he tratado en mi libro Fernando I, regente de Castilla y rey de Aragón (1407-1416), Gijón, 2012. 
lado, nos sirve para destacar el protagonismo de los eclesiásticos en las distintas facetas de gobierno, y por otro para resaltar la importancia de las relaciones personales y feudovasalláticas establecidas, en buena parte de los casos, desde la niñez.

\section{LAS CAMPAÑAS GRANADINAS DE 1407 Y DE 1410}

El apoyo de la Iglesia a las empresas bélicas de la monarquía castellana a comienzos del siglo XV se produjo en formas tan diversas como la económica, la ideológica, la espiritual, la logística o la jurídica². Sin embargo, el aspecto más evidente de la colaboración eclesiástica fue la participación de algunos miembros del episcopado en las campañas granadinas. Sin duda alguna, el más destacado por su influencia ante el infante castellano así como por los hechos de armas en los que participó fue don Sancho de Rojas, obispo de Palencia. Don Sancho había abogado y propuesto ante la reina y los grandes del reino, entre otras cosas, por la participación de los prelados «... con las personas e haciendas, é con todo lo que pudiéremos en esta guerra» ${ }^{3}$, y más tarde justificaba las razones del infante y defendía sus pretensiones. Para don Sancho de Rojas, la guerra era la ocasión propicia para demostrar la lealtad debida al rey y para reparar los errores cometidos antes contra los musulmanes. Elogia al infante por ponerse al frente de esta operación y señala que las intenciones de éste se basaban en la caridad. En primer lugar por querer ensalzar la fe católica, en segundo término por su amor a la justicia, cuya ejecución correspondía al regente, por lo que éste debía devolver al servicio y jurisdicción regia la tierra usurpada. Don Sancho apoya su defensa de la guerra en las Sagradas Escrituras. Para él la guerra era un medio a través del cual el infante demostraría su fidelidad al rey cuando éste alcanzara la mayoría de edad, por lo que no duda en comparar a don Fernando con el siervo bueno y fiel de la parábola de los talentos ${ }^{4}$. Como aquél, el infante recibió la administración de unos bienes y se veía en la obligación de incrementarlos cuando se los reclamara su señor. Para ello debía de contar con la ayuda de todos, pues era obligación de todos los fieles a Cristo combatir por su fe, sobre todo cuando los musulmanes estaban cautivando y matando a los cristianos y blasfemando sobre el nombre de

\footnotetext{
2 He tratado esos aspectos en Las relaciones exteriores de Castilla a comienzos del siglo XV. La minoría de Juan II (1407-1420), Madrid, 2013, pp. 211-218.

3 PÉREZ DE GUZMÁN, Fernán, Crónica del serenísimo príncipe don Juan, segundo rey deste nombre en Castilla y León, escrita por el noble y muy prudente caballero Fernán Pérez de Guzmán, Señor de Batres, del su Consejo, Biblioteca de Autores Españoles, Colección ordenada por don Cayetano Rosell, vol. LXVIII, t. II, Madrid, 1953. p. 281. La postura de la Iglesia sobre si estaba permitido a los clérigos y obispos tomar las armas osciló a lo largo de la Edad Media acomodándose a las circunstancias. MINOIS, Georges, L'Église et la Guerre. De la Bible à l'ère atomique, Paris, 1994, pp. 195-198.

4 «Ahé siervo bueno e fiel, en lo poco fueste fiel, muchas cosas fiaré de tí, entra en el gozo de tu señor». GARCÍA DE SANTA MARÍA, Álvar, Crónica de Juan II de Castilla, Edición de Juan de Mata Carriazo y Arroquia, Madrid, 1982, p. 75. Véase también CÁTEDRA, Pedro M., «Acerca del sermón político en la España medieval. (A propósito del discurso de Martín el Humano en las Cortes de Zaragoza de 1398)», Boletín de la Real Academia de Buenas Letras de Barcelona, 40 (1985-1986), pp. 17-47 [p. 24].
} 
Cristo. Don Fernando era para él otro Judas Macabeo por su gran confianza y fe en Dios, y como el caudillo judío el infante castellano estaba destinado a obtener la victoria sobre los infieles, pues «la fortaleça del cielo viene», por lo que don Fernando y los que con él fuesen obtendrían la recompensa en el reino de Dios ${ }^{5}$.

Don Sancho de Rojas estuvo presente en la campaña de 1407, en la que llevó a su costa 120 lanzas y 600 hombres, la mitad ballesteros y la otra mitad lanceros, por los que recibió 110.000 maravedíes ${ }^{6}$ y donde negoció con los musulmanes la entrega de Zahara ${ }^{7}$. A pesar del fracaso del ejército castellano ante Setenil transmitió a don Fernando, la idea de que regresaba victorioso de tierra y mar y de que en poco tiempo había hecho más de lo que muchos esperaban ${ }^{8}$. Don Sancho demostró sus dotes militares en los inicios de las hostilidades contra Antequera, en la batalla de la Boca del Asno el 6 de mayo, al colaborar de forma decisiva en el triunfo castellano ${ }^{9}$. En efecto, la táctica que empleó nos muestra a una persona con unas grandes dotes organizativas, como revela su decisión de asignar cada puesto de combate de antemano, sagaz al prever las dificultades que se avecinaban e inclinarse a pedir ayuda al infante, y práctico, al disponer junto con los que le rodeaban una línea de defensa compacta, combinación de caballeros y peones, y en la que tendrían bastante importancia los lanceros, una formación de haces ${ }^{10}$, destinada a resistir el asalto de la caballería enemiga ${ }^{11}$, todo ello y el que el terreno sobre el que se asentase fuese un otero facilitaron su defensa y dificultaron su conquista por los musulmanes. Don Sancho estaba al lado del infante don Fernando cuando decidió tomar la torre de Antequera el 16 de septiembre de $1410^{12}$ y fue uno de los dos castellanos

${ }^{5}$ Las ideas de este apartado se basan en lo expuesto por GARCÍA DE SANTA MARÍA, Álvar, Crónica, (1982), pp. 69-76. Según toma PÉREZ DE TUDELA VELASCO, M. a Isabel, «La «dignidad» de la Caballería en el horizonte intelectual del siglo XV», En la España Medieval. Estudios en memoria del profesor D. Claudio Sánchez-Albornoz, vol. II, 9 (1986), pp. 813-829 [p. 823], de la obra de Juan Rodríguez del Padrón, Cadira de Onor o Tratado de la nobleza y fidalguía, la esperanza de galardón estimula la virtud.

6 «A don Sancho de Rojas/obispo de Palençia, que ouo de auer el dicho año en cuenta de çient mill marauedís, que fue mi merçed de le mandar dar/ en emienda de la costa que fizo e del trabajo que tomó por mi seruiçio teniendo en la frontera de los moros/ çiento e veynte lanças, para las quales nin para alguna dellas non tenía tierra, e otrosí seysçientos omes/ de pie, los trezientos ballesteros e los trezientos lançeros, diez mill marauedís». VILLAPLANA, M. ${ }^{\text {a }}$ Asunción, «Un ajuste de cuentas del alcabalero mayor de Sevilla Pedro Ortiz (1420)», Historia. Instituciones. Documentos, I (1974), pp. 417-502 [p. 446]. VALLA, Lorenzo, Historia de Fernando de Aragón, Edición de Santiago López Moreda, Madrid, 2002, p. 90, dice que don Sancho de Rojas «... prometió que le acompañaría con un gran número de aliados».

7 GARCÍA DE SANTA MARÍA, Álvar, Crónica, (1982), p. 138.

8 VALLA, Lorenzo, Historia, p. 99.

9 BARRIENTOS, Lope de, Refundición de la Crónica del Halconero, Edición de Juan de Mata Carriazo y Arroquia, Madrid, 1946, p. 19; PÉREZ DE GUZMÁN, Fernán, Crónica, pp. 219-220; GARCÍA DE SANTA MARÍA, Álvar, Crónica, (1982), pp. 304-310.

10 LÓPEZ QUERO, Salvador, «Léxico militar en el Cancionero de Baena», Juan Alfonso de Baena y su Cancionero. Actas del I Congreso Internacional sobre el Cancionero de Baena (Baena, del 16 al 20 de febrero de 1999). Editores Jesús Luis Serrano Reyes y Juan Fernández Jiménez, Baena, 2001, pp. 259-278 [pp. 262-263], la incluye entre las situaciones bélicas.

11 PÉREZ DE GUZMÁN, Fernán, Crónica, p. 319; GARCÍA DE SANTA MARÍA, Álvar, Crónica, (1982), p. 305.

12 PÉREZ DE GUZMÁN, Fernán, Crónica, p. 309; GARCÍA DE SANTA MARÍA, Álvar, Crónica, (1982), p. 379. 
a los que los musulmanes entregaron el castillo el día $24^{13}$. En esta campaña también tuvo hombres a su costa, al margen de los que llevó de la ciudad de Palencia ${ }^{14}$.

Estas acciones de armas hicieron que el nombre de don Sancho de Rojas aparezca en la misiva que don Fernando dirigió a las ciudades comunicándoles la victoria sobre los infantes musulmanes ${ }^{15}$, o que se le incluya en el poema que compuso Gonzalo Martínez de Medina a la muerte de la reina doña Catalina; autor que utiliza las campañas contra el reino de Granada para recordar al rey que debe de apoyarse en la nobleza del reino y con ella proseguir la tarea conquistadora ${ }^{16}$.

Pérez de Guzmán menciona la presencia de un grupo de prelados en la campaña de Antequera, - aunque solo cita al obispo de Palencia y al arcediano de Guadalajara - presentes en el consejo convocado por don Fernando en Córdoba el 20 de abril de $1410^{17}$. Don Lope de Mendoza, arzobispo de Santiago también formó parte del ejército castellano en la campaña de $1410^{18}$, donde llevó gente propia ${ }^{19}$.y en la que fue uno de los grandes elegidos para ir a correr Málaga ${ }^{20}, y$ tras la caída de Antequera tomó el castillo de Cauche y ayudó a tomar la fortaleza de Xébar, donde fue herido ${ }^{21}$.

Menor seguridad existe en la participación de don Alfonso de Egea, administrador apostólico del arzobispado de Sevilla y patriarca de Constantinopla quien, según Ortiz de Zúñiga, salió el día 6 de mayo de 1410 «... con una lucida tropa a su costa» 22 .

${ }^{13}$ PÉREZ DE GUZMÁN, Fernán, Crónica, p. 331; GARCíA DE SANTA MARÍA, Álvar, Crónica, (1982), p. 389.

14 FERNÁNDEZ DE MADRID, Alonso, Silva Palentina, Ed. J. San Martín, Palencia, 1976, p. 272.

15 GARCÍA DE SANTA MARÍA, Álvar, Crónica, (1982), p. 309.

${ }^{16}$ Cancionero de Juan Alfonso de Baena, Edición crítica de José María Azáceta, vol. II, Madrid, 1966, n. 335 , pp. 739-743.

17 PÉREZ DE GUZMÁN, Fernán, Crónica, p. 316.

18 LÓPEZ FERREIRO, Antonio, Historia de la Santa A. M. Iglesia de Santiago de Compostela, vol. VII, Santiago de Compostela, 1983, nota 1, pp. 11-12. (Facsímil de la de Santiago de Compostela, 1904).

19 PÉREZ DE GUZMÁN, Fernán, Crónica, p. 322. GARCíA ORO, José, La nobleza gallega en la Baja Edad Media. Las casas nobles y sus relaciones estamentales, Santiago de Compostela, 1981, p. 30, indica que don Lope fue uno de los jefes de los caballeros gallegos. En el testamento de Fernán García Barbá de Figueroa, otorgado en el año 1473 se hace referencia en los siguientes términos a la expedición de D. Lope «As costas que tebo (Antonio García de Saavedra, padre de Fernán García) ennas sahidas que fiso con os demais fidalgos da terra en compañía do señor arçobispo et perlado de Santiago don Lope de Mendoza... contra os mouros da Andalucía fasta que se ganou a cibdad de antequeira». LÓPEZ FERREIRO, Antonio, Historia, vol. VII, nota 1, pp. 11-12.

${ }^{20}$ PÉREZ DE GUZMÁN, Fernán, Crónica, p. 324; GARCÍA DE SANTA MARÍA, Álvar, Crónica, (1982), p. 326.

21 PÉREZ DE GUZMÁN, Fernán, Crónica, p. 331; GARCíA DE SANTA MARÍA, Álvar, Crónica, (1982), pp. 392-393.

22 ORTIZ DE ZÚÑIGA, Diego, Anales eclesiásticos y seculares de la ciudad de Sevilla, Reproducción de la de 1795 con índices de José Sánchez Herrero y otros, vol. II, Sevilla, 1988, p. 325. Teniendo en cuenta la fecha que ofrece Ortiz de Zúñiga, 6 de mayo, y la muerte de Martín I, 31 del mismo mes y año, y que según García de Santa María el conocimiento de su misión —concertar una entrevista entre el rey don Martín y su sobrino el infante don Fernando- se conoció pocos días antes de la muerte del rey de Aragón, sería materialmente imposible en la época su estancia en Antequera al frente de una tropa, su ida hacia Aragón y su vuelta por mar hasta Sevilla pocos días antes del deceso. 
Entre los altos eclesiásticos del orden episcopal que acompañaron al infante desde el inicio de la campaña de 1410, estuvo don Gutierre Gómez de Toledo, arcediano de Guadalajara, del que no hay constancia que participase en ningún hecho de armas ${ }^{23}$. El arcipreste de Astudillo, Fernán Gutiérrez de los Barrios, que tomó parte con don Sancho de Rojas en la batalla de la Boca del Asno, en la que llevaba el pendón del obispo, y donde tuvo una destacada actuación ${ }^{24}$. Desempeñando distintas funciones estuvieron Gonzalo Rodríguez de Neira, arcediano de Almazán, Diego Gómez de Fuensalida, abad de Valladolid y capellán mayor del infante, así como el arcediano de Niebla, los cuales pasaron con don Fernando a Sevilla después de la campaña ${ }^{25}$. Más improbable es que estuviesen presentes el obispo de Plasencia don Vicente Arias de Balboa, y el arcediano de Olmedo, ya que se encontraban en Sevilla entre los expertos que debían dictaminar sobre el derecho del infante don Fernando al trono de Aragón ${ }^{26}$.

El obispo de Córdoba don Fernando González Deza tomó parte en 1408 en una escaramuza con forrajeadores moros, mientras el rey de Granada asediaba Alcaudete ${ }^{27}$.

Sin duda hubo muchos más eclesiásticos presentes en las campañas militares, pero no tan importantes como los citados, como fray Juan de Sevilla, religioso franciscano que redactó el testamento de Carlos Ramírez de Arellano en el real sobre Antequera el 12 de julio de $1410^{28}$.

\section{EL ASEDIO A BALAGUER, 1413}

Tras el nombramiento de don Fernando como rey de Aragón, dado a conocer el 28 de junio de 1412, hasta la ruptura de hostilidades que le enfrentó con el conde de Urgel pasó cerca de un año, por lo que don Fernando envió a Castilla a los hombres de armas que le habían ayudado a conseguir el reino, y a los que tuvo que llamar ante la actitud de don Jaime de Urgel que, entre otras cosas, contrató a

${ }^{23}$ Su permanencia al comienzo de la campaña la recoge Fernán PÉREZ DE GUZMÁN, Crónica, p. 316, y al final en GARCÍA DE SANTA MARÍA, Álvar, Crónica, (1982), p. 409. LAYNA SERRANO, Francisco, Historia de Guadalajara y sus Mendozas en los siglos XV y XVI, Guadalajara, 19932, p. 188, lo da entre los que participaron en la toma de Antequera.

${ }^{24}$ FERNÁNDEZ DE MADRID, Alonso, Silva Palentina, p. 272. El nombre de este prelado figura en OREJÓN CALVO, Anacleto, Astudillo. Convento de Santa Clara, Palencia, 1984, nota 15, p. 106.

${ }_{25} \mathrm{RAH}$., Col. Salazar y Castro, M-10, fols. 89r-94r.

26 GARCÍA DE SANTA MARÍA, Álvar, Crónica, (1982), p. 409; PANZÁN, Luis, Recordanzas en tiempo del Papa Luna (1407-1435), Edición, prólogo y notas por Gregorio de Andrés, Madrid, 1987, p. 45.

27 PÉREZ DE GUZMÁN, Fernán, Crónica, p. 305; GARCíA DE SANTA MARÍA, Álvar, Crónica, (1982), pp. 209-210.

28 SALAZAR Y CASTRO, Luis, Historia genealógica de la Casa de Lara, justificada con instrumentos y escritores de inviolable fe, vol. I, Madrid, 1696, p. 382. 
mercenarios extranjeros dispuestos a combatirle ${ }^{29}$. La derrota del capitán Basilio que estaba al frente de los ingleses que se dirigían a reforzar a don Jaime a Balaguer fue el comienzo de la implicación directa del monarca en el conflicto, que desde entonces se convirtió en guerra abierta y que reviste dos formas, la primera en la que perdominan las correrías de campo y la fase final que comprendería, ante todo, el asedio al conde de Urgel en Balaguer, en el que centraré la participación de los eclesiásticos castellanos.

Entre las personas que se encargaron de suministrar las peticiones que don Fernando hacía desde el real de Balaguer encontramos a su mujer, la reina doña Leonor y a su hijo Alfonso, junto al que estaba el obispo de León, don Alfonso de Argüello, a colaboradores castellanos habituales como el obispo de Zamora, o catalanes ganados para su causa tras su elección como rey, como Pedro de Zagarriga, arzobispo de Tarragona. Será precisamente en don Alfonso de Argüello y en mayor medida en Diego Gómez de Fuensalida, obispo de Zamora, en quienes fije la atención.

El importante papel que el obispo de León desempeñó al lado del infante don Alfonso, del que es consejero y canciller mayor ${ }^{30}$, hace que, en diversas ocasiones, las peticiones del rey se dirijan a él, aunque su hijo pueda ser el destinatario final. Así, por ejemplo, cuando se le encarga proveer al real de: «... XII cuyros de bufano adobados en blancho o de ciervo adobados en blancho... todos los quals cuyros havemos grand necessidat para los engenyos» ${ }^{31}$. En otras ocasiones recibirá una carta expresa del monarca, con el mismo contenido que la que envíaba a su hijo, instándole a remitirle cuanto antes lo que les pedía, como hizo el 2 de septiembre quejándose por la demora que tenían en proveerle de «... XXX molers o pedres, e axí mateíx LXXX quintars de coure, e XL quintars de pólvora e certes altres coses», y ya en escrito dirigido al citado obispo y al arzobispo de Tarragona que le mandasen «... X àncores de naus o de galeres. $E$ noresmenys $\mathrm{CC}$ taules de pique sien seques, de grossària de un dito o dos, les més longues e leugeres que.s puxen aquí atrobar» ${ }^{32}$, así como cincuenta quintales, no especifica de qué, para construir

29 ZURITA, Jerónimo, Anales de la Corona de Aragón, Edición de Ángel Canellas López, vol. V, Zaragoza, 1980, pp. 317-319; PÉREZ DE GUZMÁN, Fernán, Crónica, pp. 347-348.

30 Fue nombrado como tal el 29 de agosto de 1413, como tomo de ARAGÓ CABAÑAS, Antonio M. ${ }^{-}$, «La corte del Infante don Alfonso (1412-1416)», Actas y Comunicaciones II, IV Congreso de Historia de la Corona de Aragón, (Mallorca 1955), Barcelona, 1970, pp. 273-293 [p. 275]. ACA., Cancillería, reg. 2403, fol. 74, publicado en Epistolari de Ferran I d'Antequera amb els infants d'Aragó i la reina Elionor (1413-1416), Edició a cura de Carlos López Rodríguez, Valencia, 2004, n.ำ88, p. 91. Sobre este personaje se cuenta con referencias en la obra de SEVILLANO COLOM, Francisco, «Cancillerías de Fernando I y de Alfonso V', Anuario de Historia del Derecho Español, XXXV (1965), pp. 169-216 [p. 177], especialmente.

31 ACA., Cancillería, reg. 2403, fol. 101, en ARANTEGUI, José, «El sitio de Balaguer en 1413. Bajo el punto de vista del empleo de la artillería», Memorial de Artillería, Serie III, Tomo XV (1887), pp. 449-463 [p. 460].

32 GIMÉNEZ SOLER, Andrés, Don Jaime de Aragón, último conde de Urgel, en Memorias de la Real Academia de Buenas Letras de Barcelona, 7 (1901), pp. 127-441 [n.ํ CLXIV, pp. 343-344]. Epistolari, n. 99, pp. 101-102. 
una bombarda ${ }^{33}$. De 25 de septiembre es otra carta dirigida al infante y a los citados arzobispo y obispo y previendo la inminencia del ataque final y para ello el empleo de grúas y máquinas de asalto pide que le envíen «... XXX mariners, los pues abtes e destres que puscats haver aquí, los quals nós havem necessaris per al día del combat, sens los quals e les cordes e les altres coses que us havem tramese demanar, axí de viratons de ballesters, cordes e los molers, no podem en res enantar en los affers ${ }^{34}$.

Diego de Monfar también le cita junto al infante don Alfonso como uno de los principales suministradores que tenía el rey ${ }^{35}$.

Sin embargo, la labor del obispo de León, Alfonso de Argüello, no se limitó únicamente a proporcionar o facilitar materiales y hombres para tomar Balaguer, pues fue, junto a otros miembros del consejo del infante don Alfonso, quien avaló con su firma un préstamo de doce mil florines que el rey necesitaba para proseguir el cerco a esa población ${ }^{36}$. Y no menos importante, el obispo de León, que tiene acceso como miembro del consejo del infante don Alfonso a todas las cartas que le dirige su padre, en alguna de las cuales figura que no se divulgue más que a él y a otras tres personas -el arzobispo de Tarragona, Juan Fernández de Heredia y Berenguer d'Olms - ${ }^{37}$, conoce de primera mano todos los problemas que se le plantearon al rey para lograr una movilización general. Por ello, en carta que el monarca dirige a su hijo primogénito desde el real de Balaguer, el 8 de septiembre de 1413, Francesch Basset comisionado por el monarca:

Primerament, darà la letra al dit bisbe de Leó, e ab ell ensemps darà la letra al dit senyor primogènit, als quals tan solament explicarà la deliberació que.l dit senyor rey ha haüda sobre lo procés de Princeps namque, la qual és que, quant lo rey té assatjat son enemich, ha loch lo usatge... Item dirà lo dit micer Francesch al dit senyor primogènit e bisbe de Leó que lo dit senyor tramet a ell principalment per dues coses sobre lo present negoci. La primera, per explicar-lus la deliberació dessús dita... La segona, perquè vegen la ordinació de la letra ordonada sobre la convocació del dit Princeps namque, en fortificació dela qual letra, si cosa alguna s'i porà adobar per lo dit primogènit e son consell, que.s faça per tal que aquella sia yverçosament executada ${ }^{38}$.

Es decir, que la aprobación de la movilización general, como expresa el rey en su misiva, tras el acuerdo adoptado ante él, fue explicado y ratificado por los

\footnotetext{
${ }^{33}$ ACA., Cancillería, reg. 2383, fol. 161, (27 octubre 1413, Sitio de Balaguer), publicada porJIMÉNEZ CATALÁN, M., Apuntes para la historia de Balaguer, Zaragoza, 1913, Apéndice 3.ำ pp. 186-187.

34 Epistolari, n. 156, p. 146.

35 «... se trabajaba mucho en hacer gran cantidad de pólvora, y traían el salitre y piedra de azufre de Barcelona, que el infante don Alfonso y el obispo de León que estaban en él cuidaban mucho de esto y eran muy solicitados por el rey, y cada día les avisaba de la falta que tenía de semejantes cosas". MONFAR Y SORS, Diego de, Historia de los Condes de Urgel, por BOFARULL Y MASCARÓ, Próspero, Colección de Documentos Inéditos del Archivo de la Corona de Aragón, Tomo X, Barcelona, 1853, p. 492.

${ }^{36}$ Epistolari, n. 153, pp. 142-144 y n.ำ 167, pp. 153-155.

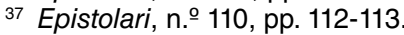

38 Epistolari, n. ${ }^{\circ} 108$, pp. 109-111.
} 
miembros del consejo de su hijo, entre los que el obispo de León tiene un importante papel. El monarca también le pidió parecer junto a los otros consejeros de su hijo acerca de la asistencia del infante al sitio de Balaguer, que debió de ser favorable, por cuanto el día 29 de octubre de 1413 don Alfonso recibía la licencia de su padre para trasladarse a Lérida ${ }^{39}$. La rendición del conde de Urgel pocos días después no hizo posible ese deseo.

Otro eclesiástico castellano de gran importancia en todo lo relacionado con el cerco a Balaguer fue el ya entonces obispo de Zamora, Diego Gómez de Fuensalida. Esto es evidente si se toma, por ejemplo, como referencia principal para la labor que este personaje llevó a cabo el documento procedente del Archivo de la Corona de Aragón, Real Patrimonio, reg. 2660, fols. XLv-LXXXv, que es en el que me voy a basar.

En efecto, don Diego proveyó al monarca del armamento que necesitaba, por ejemplo, a través de Guillén Pardo, repostero de la casa del rey que «... fue dela ciudat de Caragoza al sitio de Balaguer con el trabuco engenio e otras castellerías que leuauan» ${ }^{40}$, que es posible que transportaran cuatro carros y que entre ida, estancia y regreso tardaron dieciocho días «... dos carretas que leuauan la percha del engenyo» y «... dos carretas que leuauan el trabuquo e cuerdas e otras artellerías» ${ }^{41}$. Al obispo de Zamora le debían de remitir tres ingenios de los mejores con todos sus pertrechos los jurados y hombres buenos de la ciudad de Calatayud $^{42}$. Además hizo compras de otras armas como cinco que constan de ballestas que también envío: una de tres, a razón de seis florines cada una ${ }^{43}$, un número indeterminado de ballestas de torno, cajones de viratones y «... otras artellerías ${ }^{44}$, tres ballestas de torno y dos de cinfonia ${ }^{45}$, y otras dos compras de dos ballestas de torno ${ }^{46}$ y de otras dos sin especificar el tipo ${ }^{47}$. Distintos pertrechos como cuerdas de cáñamo ${ }^{48}$ y cincuenta paveses de barrera, a razón de florín y medio cada uno ${ }^{49}$.

Envió a dos hombres del lugar de Torrellas que debían de servir en el sitio a Balaguer por dos meses, a razón de tres sueldos jaqueses por día ${ }^{50}$, y a cincuenta y seis ballesteros de Tarazona por quince días ${ }^{51}$. Sin duda a instancia regia,

39 ARAGÓ CABAÑAS, Antonio M. ${ }^{\text {a }}$ «El infante Alfonso de Aragón no asistió a la toma de Balaguer (1413)», Estudios de Edad Media de la Corona de Aragón, VII (1962), pp. 623-636 [p. 627].

40 ACA., Real Patrimonio, reg. 2660, ejercicio del año 1413 a 1414, de febrero a febrero, fol. XLIv.

41 ACA., Real Patrimonio, reg. 2660, fol. Lr.

42 ARANTEGUI, José, «El sitio...», p. 456.

43 ACA., Real Patrimonio, reg. 2660, fol. XLIIIr.

44 ACA., Real Patrimonio, reg. 2660, fol. XLIIIv.

45 ACA., Real Patrimonio, reg. 2660, fol. XLIVr.

46 ACA., Real Patrimonio, reg. 2660, fol. XLIVv.

47 ACA., Real Patrimonio, reg. 2660, fol. LVr.

48 ACA., Real Patrimonio, reg. 2660, fol. XLIXr.

49 ACA., Real Patrimonio, reg. 2660, fol. XLVv.

50 ACA., Real Patrimonio, reg. 2660, fol. XLIVr.

51 ACA., Real Patrimonio, reg. 2660, fol. XLVIr. 
pues la correspondencia debía de ser bastante frecuente, como consta por varias noticias al respecto ${ }^{52}$, dispuso enviar en varias ocasiones espías al sur de Francia, al igual que hizo el monarca ${ }^{53}$. La primera vez de que hay constancia al castellano Juan de Miranda y a Pedro Navarro, del reino de Navarra, a las ciudades de Bayona y a Olorón «... por saber e sentir si se amassauan gent darmas ni si don Anthon de Luna hera entre daquellas partidas» ${ }^{54}$, más tarde, según parece a "Pero Nauares hestant enla ciudat de Huescha el qual de mandamiento e hordenación del sido senyor fue por espía a Bordeu e aotras partes enla rebellión o guerra que don Jayme Durgell fazía contra el senyor rey» 55 , y la tercera «... a Pedro de Mont Cler barbero dela ciudat de Caragoca el qual de mandamiento del dito senyor obispo fue dela ciudat de Caragoca al castiello de Loharre por espía enel mes de setiembre más cerqua passado por saber e sentir do Antón de Luna si hera enel castiello de Loharre ni que si fazía» 56 .

Cuando el cerco a Balaguer se acercaba a su final y en vista de las conquistas del bando real encargó a «... Pero Ferrer pintor hestant enla ciudat de Caragoca... $\mathrm{C}$ pendones reales... por ponerlos enlas heredades bienes casas e castiellos delos rebeldes que prendían e ocupauan amanos dela cort del dito senyor rey» ${ }^{57}$. Lo que quizás tenga que ver con la alta responsabilidad que debió de ejercer en la incautación de los bienes que habían pertenecido a don Jaime de Urgel y a sus partidarios ${ }^{58}$. En tal sentido conocemos que por orden suya se hacen varios pagos a personas que tomaron esos bienes en las montañas de Jaca ${ }^{59}$, en «Quart a Uilla Nueua de Burgacut ala uilla dAlagón e alos lugares del río Dexalón e del río de Berga et... dallá el río de Ebro alas uillas de Exea a Tahust a Uncastiello a Sos a Gordún e a otros lugares de la montanya de Jaqua» ${ }^{60}$, y en otros lugares sin concretar, como ocurrió con Estebán Zaragozano, portero de la casa del rey ${ }^{61}$.

Por sus manos pasaron también los pagos a importantes miembros de la nobleza sobre todo aragonesa que habían servido al rey en el asedio a don Jaime de Urgel en Balaguer, gracias a lo cual conocemos las aportaciones de cada uno de

52 «Ítem dio de mandamiento e hordenación del dito senyor obispo a Ffrancisquo de Seuilla que fue con letras del dito senyor obispo al sitio de Balaguer las quales levó al senyor rey». ACA., Rea Patrimonio, reg. 2660, fol. XLIlv. «... correu que fue de Caragoca a Leyda enel mes de nouiembre más cerqua passado con letras del senyor obispo que leuó al senyor rey». ACA., Real Patrimonio, reg. 2660, fol. LXXIIIr.

53 ACA., Real Patrimonio, reg. 2660, fol. LXXVIr.

54 ACA., Real Patrimonio, reg. 2660, fol. XLIlv.

55 ACA., Real Patrimonio, reg. 2660, fol. LIv.

56 ACA., Real Patrimonio, reg. 2660, fols. LXXIIv-LXXIIIr

57 ACA., Real Patrimonio, reg. 2660, fol. XLIVv.

58 Antes del cerco a don Jaime en Balaguer y, por lo tanto, de su derrota, existe constancia documental de una carta del rey a Juan Jiménez de Cerdán, justicia de Aragón, en la que le ordena librar los bienes confiscados a don Jaime y a don Antonio de Luna en manos de Diego Gómez de Fuensalida. GIMÉNEZ SOLER, Andrés, Don Jaime de Aragón, n.ํXXXIX, pp. 318-319.

59 ACA., Real Patrimonio, reg. 2660, fol. Lir y LIIr.

60 ACA., Real Patrimonio, reg. 2660, fol. LIlv.

61 ACA., Real Patrimonio, reg. 2660, fol. LIVr. 
ellos. Así, por ejemplo, Jaime de Luna que sirvió con quince hombres de caballo armados $^{62}$, Juan Martínez de Luna con cincuenta ${ }^{63}$, los mismos que Fernández de Heredia ${ }^{64}$, mientras que con cien sirvieron Gil Ruiz de Lihori ${ }^{65}$, Pedro Jiménez de Urrea $^{66}$ y Juan de Bardaxí ${ }^{67}$.

Así pues, podemos concluir este apartado señalando las importantes aportaciones de estos eclesiásticos a las campañas guerreras de don Fernando de Antequera, muy diferentes las de la etapa castellana de la del periodo aragonés. En las primeras, las escasas noticias nos muestran a unos obispos guerreros, -en consonancia con otros ejemplos de siglos anteriores, como el XIII y el XIV, e incluso de época posterior- de ellos el ejemplo más consumado fue don Sancho de Rojas y en menor medida el arzobispo de Santiago, don Lope de Mendoza, ambos de linajes nobles. Esto contrasta con lo que se observa en la campaña de Balaguer donde los altos eclesiásticos castellanos, al servicio de Fernando I de Aragón, desempeñan un papel más discreto, pero no menos decisivo e importante, en la retaguardia y ocupándose de la logística de la guerra. En este último caso es evidente también, de acuerdo con los personajes citados, la relevancia que tuvieron como centros de suministro Barcelona y Zaragoza, casi equidistantes de Balaguer, y que es donde residían por el momento el obispo de León y el de Zamora, respectivamente. Una diferencia que se observa, fruto sin duda, del distinto tipo de documentación utilizado, es que en el caso del obispo de León se disponga de solicitudes que parten directamente del rey, mientras que lo que tiene que ver con el obispo de Zamora se alude a su petición por el monarca, de ahí que por ejemplo no exista ningún documento en que don Fernando lo reprenda. También es evidente que desde Barcelona se atiende y se satisfacen exigencias de armamento más importante, mientras que desde Zaragoza el obispo don Diego en algún caso hace pequeños envíos, por ejemplo de ballestas, que poco a poco va comprando.

\section{BREVE PERFIL BIOGRÁFICO DE LOS OBISPOS}

No se puede entender por qué fueron éstos y no otros los eclesiásticos que tuvieron un papel tan destacado en las acciones citadas sino se tiene en cuenta su trayectoria anterior, sobre todo por su estrecha relación con el infante don Fernando desde su infancia y juventud, y con el que estuvieron vinculados muchos de sus servicios diplomáticos ${ }^{68}$. Así habría ocurrido con los tres personajes

62 ACA., Real Patrimonio, reg. 2660, fol. XLVIIIV.

63 ACA., Real Patrimonio, reg. 2660, fol. XLVIIv.

64 ACA., Real Patrimonio, reg. 2660, fol. LXr.

65 ACA., Real Patrimonio, reg. 2660, fol. LXv y LXIv.

66 ACA., Real Patrimonio, reg. 2660, fol. LXVIr.

67 ACA., Real Patrimonio, reg. 2660, fol. LXVIIv.

68 Véase, por ejemplo, VILLARROEL GONZÁLEZ, Óscar, «Eclesiásticos en la diplomacia castellana en el siglo XV», Anuario de Estudios Medievales, 40/2 (2010), pp. 791-819. 
objeto de atención: Sancho de Rojas, Alfonso de Argüello y Diego Gómez de Fuensalida.

\section{a) El obispo de Palencia y arzobispo de Toledo}

Sancho Sánchez de Rojas era hijo del señor de la localidad palentina de Monzón, por lo que pertenecía a la mediana nobleza. Se formó en las universidades de Salamanca y Toulouse, a los diecinueve años figuraba como canónigo de Burgos y de Salamanca y una de sus primeras apariciones públicas fue como representante castellano en las negociaciones entre Portugal y Castilla en $1399^{69}$. La vinculación entre don Sancho de Rojas, obispo de Palencia y después arzobispo de Toledo, y don Fernando fue muy estrecha ${ }^{70}$, por lo que aquí respecta, se puede remontar hasta 1406, tras la muerte de Enrique III. A don Sancho le correspondió acompañar al infante, en su calidad de oídor de la Chancillería, con motivo de la primera división administrativa del reino en $1407^{71}$. Al año siguiente, 1408, y desde el mismo momento en que el infante contrasta su opinión con él se convertirá en el instrumento que emplee para alcanzar el maestrazgo de la Orden de Alcántara para su hijo don Sancho ${ }^{72}$. Don Sancho, como obispo de Palencia, fue uno de los doce prelados castellanos que manifestaron su adhesión a Benedicto XIII en $1409^{73}$. En 1410 tomó parte activa y muy principal en la toma de Antequera, por la que parece que fue recompensado con el título de conde de Pernía, que no llegó a utilizar nunca, para él y para sus sucesores ${ }^{74}$. En 1411, fue como embajador del Consejo real de Castilla ante el Parlamento de Aragón para

69 Estos datos proceden de BECEIRO PITA, Isabel, «Las negociaciones entre Castilla y Portugal en 1399», Revista da Faculdade de Letras, II Série, vol. XIII (1996), pp. 149-185 [pp. 180-181].

70 «Fue muy acepto e allegado al Rey Don Fernando de Aragon». PÉREZ DE GUZMÁN, Fernán, Generaciones, Semblanzas, (1953), p. 719.

71 PÉREZ DE GUZMÁN, Fernán, Crónica, p. 284; GARCÍA DE SANTA MARÍA, Álvar, Crónica, (1982), p. 90.

72 PÉREZ DE GUZMÁN, Fernán, Crónica, pp. 310-311; GARCÍA DE SANTA MARÍA, Álvar, Crónica, (1982), pp. 256-257.

73 ACB., Cisma de Occidente, perg. 468, regesto en BAUCELLS I REIG, Josep, El fons «Cisma d'Occident» de l'Arxiu Capitular de la Catedral de Barcelona. Catàleg de còdex i pergamins, Barcelona, 1985, n.으 375, p. 189.

${ }^{74}$ AZCONA, Tarsicio de, La elección y reforma del episcopado español en tiempo de los Reyes Católicos, Madrid, 1960, pp. 42-43, que lo debe tomar de una edición anterior a la manejada por nosotros de FERNÁNDEZ DE MADRID, Alonso, Silva Palentina, p. 272. En ambas obras consta expresamente que la donación se debió a su participación en la campaña militar de 1410. Mientras que FERNÁNDEZ DEL PULGAR, Pedro, Historia secular, y eclesiástica de la civdad de Palencia..., vol. II, Madrid, 1680, pp. 87-92, discrepa de sí se debió a los servicios prestados en la campaña sobre Antequera o la embajada que hizo a Aragón en defensa de los derechos del infante don Fernando al trono de aquel reino. Y quienes no proporcionan ninguna fecha en concreto ni lo relacionan con ningún hecho son: BLANCO DÍEZ, Amancio, «Los Arcedianos y Abades del Cabildo Catedral de Burgos», Boletín de la Real Academia de la Historia, CXXX (1952), pp. 267-298, y CARANDE THOVAR, Ramón, «El obispo, el concejo y los regidores de Palencia (1352-1422). Aportación documental sobre el gobierno de una ciudad en la Edad Media», Siete Estudios de Historia de España, Barcelona, 1971, pp. 55-93 [p. 61], que creo que se refiere a que las tierras de Pernía estaban en poder de los obispos de Palencia desde tiempos de Enrique III. 
defender los derechos del infante don Fernando al trono de ese reino ${ }^{75}$, y al año siguiente acudió con el mismo cometido, pero bajo mandamiento regio ${ }^{76}$. A partir de la elección de don Fernando como rey de Aragón, a finales de junio de 1412, se quedó en Castilla gobernando las provincias que le habían correspondido al infante-rey y además fue una especie de comisionado, sin reconocimiento institucional, en las provincias que la reina-regente gobernaba ${ }^{77}$. Por lo tanto, los servicios de don Sancho de Rojas a don Fernando no se limitaron a sus años de regencia en Castilla sino que permaneció vinculado a él hasta su muerte en 1416 y después a sus hijos.

Las ayudas de don Sancho de Rojas a don Fernando, y en aquel momento también a Benedicto XIII, le proporcionaron el arzobispado de Toledo, por iniciativa de la reina de Castilla y del rey de Aragón ${ }^{78}$, con fecha 26 de junio de $1415^{79}$, y con su nombramiento la remodelación más amplia de los obispados castellanos durante la minoría de Juan II, hasta nueve ${ }^{80}$. Unos días más tarde, el 9 de julio, el rey Fernando I desde Valencia autorizaba a su mujer, doña Leonor, a recompensar al citado prelado con la merced del lugar de Villota de la Bodega, en la Merindad de Saldaña ${ }^{81}$.

Su vinculación con don Fernando trasciende a su persona pues sus sobrinos, de los que sería el protector: el mariscal Pedro García de Herrera y sobre todo Diego Goméz de Sandoval, serán hombres de confianza del rey de Aragón, tanta que a este último le concedió el Adelantamiento mayor de Castilla ${ }^{82}$ y él se consi-

75 PÉREZ DE GUZMÁN, Fernán, Crónica, p. 336. Acta Curiarum Regni Aragonum. Parlamentos del Interregno (1410-1412). Actas del Parlamento de Alcañiz-Zaragoza (1411-1412), Tomo VII, vol. I, Edición a cargo de José Ángel Sesma Muñoz, Zaragoza, 2011, pp. 241-244.

76 PÉREZ DE GUZMÁN, Fernán, Crónica, p. 342. Acta Curiarum Regni Aragonum, Tomo VII, vol. I, pp. 266.

77 PÉREZ DE GUZMÁN, Fernán, Crónica, p. 346.

78 PÉREZ DE GUZMÁN, Fernán, Crónica, p. 362. El nombramiento habría tenido lugar el 26 de junio de 1415 como consta en Diccionario de Historia Eclesiástica de España, (DHEE) vol. IV, Madrid, 1975, p. 2570. VILLARROEL GONZÁLEZ, Óscar, «Las intervenciones regias en las elecciones episcopales en el reinado de Juan II de Castilla (1406-1454). El caso de los arzobispos de Toledo", Anuario de Estudios Medievales, 31/1 (2001), pp. 147-190 [pp. 157-162], y del mismo autor Las relaciones entre la monarquía y el arzobispado de Toledo en época de Juan II de Castilla (1406-1454), Toledo, 2002, p. 16, y El rey y la iglesia castellana. Relaciones de poder en el reinado de Juan II 1406-1454, Madrid, 2011, pp. 81-82. MILLET, Hélène, y MORAW, Peter, «Les clers dans I'État», Les Élites du pouvoir et la construction de I'État en Europe, sous la direction de Wolfgang Reinhard, Paris, 1996, pp. 237-257 [p. 255], señalan que para un príncipe la manera más habitual de recompensar los méritos de un religioso consistía en usar su influencia para hacerle progresar en la jerarquía eclesiástica.

79 RIVERA RECIO, Juan Francisco, Los arzobispos de Toledo en la Baja Edad Media (S. XII-XV), Toledo, 1969, p. 105.

80 GONZÁLEZ SÁNCHEZ, Santiago, «Los obispos castellanos en los inicios del siglo XV (1407-1420)», Estudios sobre Patrimonio, Cultura y Ciencias Medievales, 15 (2013), pp. 187-214.

${ }^{81}$ ADM., leg. 104, n. 5, reg: GONZÁLEZ MORENO, Joaquín, Catálogo del Archivo General de la Casa Ducal de Medinaceli, Tomo III, Sevilla, 1973, p. 113.

82 Publicado parcialmente por LÓPEZ MATA, Teófilo, La ciudad y castillo de Burgos, Burgos, 1949 , p. 65. 
deraba «... su criado e fechura» ${ }^{83}$, permaneciendo después vinculado al infante don Juan de Aragón.

Desde un punto de vista estrictamente eclesiástico y al margen de su currículum vitae es interesante destacar que don Sancho de Rojas durante su etapa como obispo de Palencia convocó dos sínodos provinciales, el primero el 4 de mayo de 1411 y el segundo el 3 de mayo del año siguiente ${ }^{84}$, sin embargo de ello no se puede deducir que tuviera un importante celo pastoral, pues sus ocupaciones políticas en la corte le impidieron acudir personalmente por lo que los celebró su vicario general en su nombre. Benedictinista convencido, al menos hasta bien entrado 1416, llama la atención por su antagonismo con la postura mantenida por Fernando I de Aragón en sus últimos meses de vida y cuesta trabajo creer que su fidelidad a Benedicto XIII se resquebrajase por los contactos que mantuvo con los enviados por el Concilio de Constanza a la corte castellana en la primera mitad de $1416^{85}$. Su afán por mandar ${ }^{86}$, concuerda con su actuación tras la elección de Martín $\mathrm{V}$ como pontífice, adhiriéndose poco después a su obediencia.

Sin duda, quedan muchísimos aspectos por tratar de la figura de don Sancho y su importancia a todos los niveles en estos años y en los posteriores, unos son más o menos evidentes a través de las crónicas reales, otros se pueden entrever a través de las misivas que dirigió a don Fernando ${ }^{87}$, mientras que otros como su

83 BNP., Ms. 216, fols. 85v-87r, publicado por GARCÍA, Michel, "El historiador en su taller en Castilla, a principios del siglo XV. Edición y comentario del Ms Esp. 216 de la Bibliothèque Nationale de Paris", Atalaya. Revue Française d'Études Médiévales Hispaniques, 10 Automne (1999), pp. 9-180 [n.ำ12, pp. 166-167].

${ }^{84}$ SÁNCHEZ HERRERO, José, «Los Concilios provinciales y los Sínodos diocesanos españoles. 1215-1550», Quaderni Catanesi di Studi Classice e Medievali, año IV, n. 7 (1982), pp. 111-197 [p. 176 ]. Synodicon Hispanum. VII Burgos y Palencia, GARCÍA Y GARCÍA, Antonio (dir), Madrid, 1997, n. 10, p. 409 y n.․ 11 , pp. 411-418.

${ }^{85}$ Esto es lo que afirma FRENKEN, Ansgar, «El trabajoso y difícil camino hacia la unión: Sancho Sánchez de Rojas, arzobispo de Toledo, y el papel clave que jugó en la extinción del gran cisma de Occidente en el reino de Castilla», En la España Medieval, 32 (2009), pp. 51-83 [p. 72], aunque indica no poder datar con precisión el momento en que se apartó definitivamente de la posición favorable a Benedicto y a la unión, señalando también que esta «... suposición que goza de mucha probabilidad; pero que no puede demostrarse documentalmente». Lógicamente con argumentos tan endebles y existiendo pruebas en contrario, tanto de años precedentes como de aquel mismo momento, es difícil de aceptar. Creo que lo que pudo darse en el prelado fue una postura favorable a la participación castellana en el Concilio de Constanza, siendo más cuestionable su desafección a la causa de Benedicto XIII. Así, por ejemplo, el 2 de enero de 1416, recibió una carta de Pedro de Comuel comunicándole de parte de Benedicto XIII el estado de los negocios, en la que se hace responsable a Diego Fernández de Vadillo del alejamiento del rey de Aragón de la causa de Benedicto XIII. De esta carta da noticia PUIG Y PUIG, Sebastián, Episcopologio Barcinonense. Pedro de Luna último Papa de Aviñón (1387-1430), Barcelona, 1920, p. 563.

86 PÉREZ DE GUZMÁN, Fernán, Generaciones, Semblanzas, p. 719.

87 He recogidos algunas de ellas en mi artículo «Documentos del reinado de Fernando I de Aragón relativos a Castilla (1412-1420) ", Boletín de la Real Academia de la Historia, Tomo CCVIII, Cuaderno III (2011), pp. 343-381. 
vertiente caritativa ${ }^{88}$, su labor artístico-cultural ${ }^{89}$, sus fundaciones ${ }^{90}$ o su deseo de no perder poder económico ${ }^{91}$ quedan más ocultos.

\section{b) El obispo de León}

Fray Alfonso de Argüello de la orden de San Francisco de la que fue Ministro Provincial en Castilla, obispo de León, tiene un perfil menos político que don Sancho de Rojas. Su vinculación con don Fernando también se remonta a su etapa como infante de Castilla antes de ser regente del reino, cuando fue su confesor ${ }^{92}$, lo que sin duda estuvo en el origen y en el protagonismo político que tuvo más tarde. De sólida formación intelectual, fue maestro en Teología y catedrático de vísperas en la Universidad de Salamanca, es uno de los embajadores que Enríque III envío a Aviñón ante el pontífice para tratar sobre la resolución del Cisma de la Iglesia, en $1401^{93}$. El 7 de agosto de 1403 Benedicto XIII le confirió el obispado de León en el que permaneció hasta el 19 de julio de 1415 ${ }^{94}$. En 1405 llegó ante la corte pontificia en Génova, donde también se encontraba don Alfonso de Egea, arzobispo de Sevilla. El 21 de septiembre de 1406 convocó sínodo en la diócesis

88 «El Obispo D. Sancho de Rojas hizo donación de unas casas llamadas de la Sinagoga, de la cofradía de Sant Salvador para hacer un hospital «a onra y loor del dicho Senor Sant Salvador». (4 febrero 1415). FRANCIA LORENZO, Santiago, Archivo Capitular de Palencia. Catálogo serie II, vol. I. Actas Capitulares (1413-1467), Palencia, 1989, n. 84, p. 30.

89 SÁNCHEZ CATÓN, Francisco Javier, «El retablo viejo de San Benito el Real de Valladolid en el Museo del Prado", Archivo Español de Arte, XIV (1940-1941), pp. 272-278. COLOMBÁS, García C., «El Libro de los bienhechores de San Benito de Valladolid», Studia Monastica, V (1963), pp. 305-404 [pp. 344-345]. YARZA LUACES, Joaquín, La nobleza ante el rey. Los grandes linajes nobiliarios castellanos y el arte en el siglo XV, Madrid, 2003, pp. 258-260. HERRÁEZ ORTEGA, M. a Victoria, "Castilla, el Concilio de Constanza y la promoción artística de don Sancho de Rojas», Goya, 334 (2001), pp. 5-19. OLIVARES MARTÍNEZ, Diana, «Albornoz, Tenorio y Rojas: las empresas artísticas de tres arzobispos de Toledo en la Baja Edad Media. Estado de la cuestión», Estudios Medievales Hispánicos, 2 (2013), pp. 129-174, en especial las páginas 148-160.

90 LOP OTÍN, M. a José, El Cabildo catedralicio de Toledo en el siglo XV: aspectos institucionales y sociológicos, Madrid, 2003, pp. 358-361. HERRÁEZ ORTEGA, M. ㅋ Victoria, «La fundación y dotación de la capilla de San Pedro en la catedral de Toledo», Laboratorio de Arte, 25 (2013), pp. 79-96.

91 AGS., Patronato Real, leg. 58, n. 45 y RAH., 9/4259, Copias de documentos, fols. 595 (extracto), el documento en fols. 597-611. Transcrito en parte por ESTEBAN RECIO, M. ${ }^{\text {a }}$ Asunción, Palencia a fines de la Edad Media. Una ciudad de señorío episcopal, Valladolid, 1989, p. 143. Según toma la autora de un documento procedente del AMPa., Arm. II, leg. III, n. ํ⒌ Esta carta de Juan II está inserta en una confirmación de Felipe II del año 1564. Noticia de la concesión sin especificar cantidades en ACPa., Arm. II, leg. 2, n.ำ 15, regesto en LEÓN TELLO, Pilar, Los judíos de Palencia, Palencia, 1967, n. 92, pp. 120-121.

92 LÓPEZ FERNÁNDEZ, P. Atanasio, "Confesores de la familia real de Castilla», Archivo Ibero Americano, XXXI (1929), pp. 5-75 [p. 57]; NIETO SORIA, José Manuel, Iglesia y génesis del Estado moderno en Castilla 1369-1480, Madrid, 1993, p. 425.

${ }_{93}$ VÁZQUEZ, Isaac, «Repertorio de franciscanos españoles graduados en Teología durante la Edad Media», Repertorio de Historia de las Ciencias Eclesiásticas en España. 3. Siglos XIII-XVI, Salamanca, 1971, pp. 235-320 [n. 7, p. 239]. NIETO SORIA, José Manuel, Iglesia y génesis, p. 425. Como confesor del infante lo cita el P. LÓPEZ FERNÁNDEZ, Atanasio, “Confesores...», p. 57. Las misiones diplomáticas como procurador castellano en Aviñón en 1401 y su participación en las negociaciones con el papado en 1402, las señala OCHOA BRUN, Miguel Ángel, Historia de la diplomacia española, vol. I, Madrid, 1990, p. 228.

94 DHEE, vol. II, Madrid, 1975, p. 1284. 
de León ${ }^{95}$ y el 3 de diciembre del mismo año autorizó la redacción de las ordenanzas del hospital de San Lázaro de León, ya «... que no se gobernaba en la manera que debía, ni los enfermos eran bien tratados ${ }^{96}$. Sería aproximadamente entre 1405 y 1406 cuando el obispo de León tuvo problemas con Diego Fernández de Quiñones, pues parece que tanto él como sus vicarios les ponían entredicho cada vez que él y sus hombres estaban en la ciudad y no se lo quitaban hasta que se marchaban de ella, provocando gran perjuicio en la administración de la justicia ${ }^{97}$. En cualquier caso, las relaciones con el obispo tenían que ser cuanto menos difíciles, pues se enfrentó con Juan Sánchez de Guzmán, alcalde por el rey en el Adelantamiento de León, al que acusaba de entrometerse en los asuntos de la Igle$\mathrm{sia}^{98}$. A comienzos de 1407 se encontraba en Segovia en la ceremonia de juramento de los tutores de Juan $\|^{99}$, y poco después la corte castellana acordó enviarle como embajador, junto con Pero Niño, a Francia, con el fin de ratificar el tratado entre ambos reinos y que no se llevó a cabo por razones desconocidas, y no, como señala Díez de Games, por los deseos bélicos de Pero Niño en relación con los musulmanes granadinos ${ }^{100}$. En 1408-1409 acudió al Concilio de Perpiñán, convocado a instancias de Benedicto XIII ${ }^{101}$. En 1409 ratifica junto con otros trece obispos y arzobispos la declaración del clero de Castilla favorable a la obediencia a Benedicto XIII:

... atendiendo los daños gravísimos que podía ocasionar a las ánimas el estado de cisma actual, agravado por la sustracción de la obediencia de Francia y atendiendo su obligación de dar ejemplo de obra de palabra a los fieles, renuevan ahora y para siempre su obediencia a Benedicto XIII, el único y verdadero vicario de Dios en la tierra ${ }^{102}$.

En agosto de ese mismo año, 1409, Rodrigo Fernández, procurador del abad y monjes de Sahagún, comparece para quejarse ante Benedicto XIII de los agravios que les han inferido don Alfonso de Argüello, obispo de León, y García Rodríguez de Carreño, maestrescuela de León, a sus representados ${ }^{103}$. El 18 de agosto

95 SÁNCHEZ HERRERO, José, «Los Concilios...», p. 168. Sin proporcionar más que el año en una obra anterior del mismo autor «Los sínodos de la diócesis de León en los siglos XIII al XV», León y su Historia. Miscelánea Histórica, III, León, 1975, pp. 165-262 [p. 179].

96 RISCO, Manuel, España Sagrada, Theatro geographico-histórico de la Iglesia de España. Origen, divisiones, y límites de todas sus Provincias. Antigüedad, Translaciones, y estado antigüo y presente de sus Sillas, con varias disertaciones críticas. De la Santa Iglesia de León, Tomo XXXVI, Madrid, 1767, p. 46.

97 SANTAMARTALUENGOS, José M. ${ }^{\text {a }}$, Señorío y relaciones de poder en León en la Baja Edad Media. Concejo y cabildo catedral en el siglo XV, León, 1993, p. 135.

98 SANTAMARTALUENGOS, José M. ${ }^{-}$, Señorío y relaciones, p. 133.

99 GARCÍA DE SANTA MARÍA, Álvar, Crónica, (1982), p. 45.

100 DÍEZ DE GAMES, Gutierre, El Victorial. Crónica de don Pero Niño Conde de Buelna, Edición y estudio de Juan de Mata Carriazo, Madrid, 1940, p. 290.

101 BELTRÁN DE HEREDIA, Vicente, Cartulario de la Universidad de Salamanca (1218-1600) I, Salamanca, 1970, p. 251.

102 ACB., Cisma de Occidente, perg. 468, regesto en BAUCELLS I REIG, Josep, El fons, n.ํ 375, p. 189.

103 AHN., Clero. Papeles, leg. 2689, regesto en ÁLVAREZ PALENZUELA, Vicente Ángel; SÁNCHEZ MARTÍN, Margarita; SUÁREZ BILBAO, Fernando, y ROMERO PORTILLA, Paz, Colección diplomática del monasterio de Sahagún VII (1300-1500), León, 1997, n.ำ2710, p. 177. 
de 1410 se dio en Segovia sentencia arbitraria en la contienda existente entre el obispo, deán y cabildo de León, por una parte, y la ciudad de León, por otra. La ciudad de León reclamaba la jurisdicción de Valdevernesga y de otros lugares y la reducción del derecho de Cancillería, del que el obispo mandaba llevar más de lo que era costumbre, así como la derogación de las constituciones que don Alfonso de Argüello había establecido y eran perjudiciales a la ciudad. El citado obispo se quejaba de que la ciudad había hecho ligas y estatutos contra él y sus familiares y había ordenado que no se pagasen ciertos dineros para la obra de la iglesia ${ }^{104}$. En 1410 y en 1411 figura como canciller mayor del infante don Fernando ${ }^{105}$, aunque en este último año ya pudo desempeñar el mismo cargo con su hijo don Alfonso $^{106}$. El obispo de León estuvo también presente en las alegrías que se organizaron en Cuenca en 1412, con motivo de la elección del infante don Fernando como rey de Aragón. Las fiestas comenzaron tras la lectura de la Sentencia de Caspe, la mañana del día siguiente, 29 de junio ${ }^{107}$, con el juramento y homenaje de los mensajeros de los reinos de Aragón al nuevo monarca, en la catedral de Cuenca y siguieron con la bendición de las banderas de Aragón en el altar y la celebración de una misa de acción de gracias por don Alfonso de Argüello ${ }^{108}$. El citado prelado figura como consejero regio en las Cortes de Barcelona, que se prolongaron entre finales de 1412 y comienzos de $1413^{109}$, año en que, como se ha señalado antes, debió de permanecer gran parte en Barcelona con el infante don Alfonso y ocupado en cuestiones de índole militar. El 29 de noviembre de 1413 estuvo presente como miembro del consejo real en la causa contra el conde don Jaime de Urgel en Lérida ${ }^{110}$. En febrero de 1414 asistió a la ceremonia de coronación de don Fernando como rey de Aragón en Zaragoza ${ }^{111}$, el 17 de abril de ese año el monarca dirigía una carta a su consejero y tesorero Fernando de la Cavallería, mandándole que pagase a don Alfonso de Argüello, obispo de León, consejero y canciller de su hijo primogénito, la cantidad de 1.000 florines que él había dado de su propio dinero para su coronación ${ }^{112}$, y se encontraba junto al infante don Alfonso, en la ciudad de Zaragoza, el 9 de diciembre, cuando el infante aceptó la donación que hizo su padre a Diego Gómez de Sandoval de la villa de Lerma ${ }^{113}$. Todo o casi todo el año 1414 debió de permanecer en Zaragoza, donde el infante don Alfonso

104 RISCO, Manuel, España Sagrada, pp. 46-48.

105 CAÑAS GÁLVEZ, Francisco de Paula, La burocracia regia durante el reinado de Juan II de Castilla: Estudio prosopográfico e itinerario, Tesis doctoral, Universidad Complutense, vol. I, Madrid, 2005, p. 11.

106 Según CAÑAS GÁLVEZ, Francisco de Paula, La burocracia regia, vol. I, p. 11, lo ejerció entre 1411-1426. Sin indicar una fecha concreta SEVILLANO COLOM, Francisco, «Cancillerías de Fernando |», p. 177.

107 Aunque la elección se hizo el día 24 de junio, como pone de manifiesto GIMENO BLAY, Francisco M., El Compromiso de Caspe (1412). Diario del proceso, Zaragoza, 2012, n.ํ 4, pp. 460-463.

108 PANZÁN, Luis, Recordanzas, pp. 100-103.

109 ZURITA, Jerónimo, Anales, p. 313.

110 ZURITA, Jerónimo, Anales, p. 377.

111 PÉREZ DE GUZMÁN, Fernán, Crónica, p. 358.

112 ACA., Cancillería, reg. 2413, fol. 46v, (1414 abril 17, Zaragoza).

113 BZ., Miró, carp. M-12/180. 
se convirtió en administrador de justicia y su padre impuso unas nuevas ordenanzas $^{114}$. En 1415 se encontró entre los altos eclesiásticos presentes en las bodas de los infantes Alfonso de Aragón y María de Castilla en Valencia ${ }^{115}$. En junio de ese mismo año, con motivo del traslado de don Sancho de Rojas de la sede palentina a la toledana, fray Alfonso de Argüello pasó a la diócesis de Palencia, que ocupó entre el 19 de agosto de 1415 y el 7 de junio de $1417^{116}$, y que suponía una gran promoción a su carrera eclesiástica y una reordenación más favorable a los intereses de don Fernando en el reino de Castilla. En 1415 también acompañó al rey de Aragón a su entrevista con el emperador Segismundo y el papa Benedicto XIII en Perpiñán «El obispo de palençia que es agora que solia ser de leon» ${ }^{117}$, siendo uno de los dos comisionados que don Fernando nombró para viajar ante la reina de Castilla y explicarle los negocios sobre la unión de la Iglesia y que por el poder que el rey de Aragón tenía del de Castilla, en este reino, se ejecutasen con rapidez los actos concordados acerca de la unión ${ }^{118}$. La trayectoria posterior de este prelado continuó en estrecha vinculación con los Trastámara aragoneses y ocupó sucesivamente las mitras de Sigüenza y de Zaragoza, donde murió en extrañas circunstancias nunca aclaradas.

\section{c) El abad de Valladolid y obispo de Zamora}

La vinculación de Diego Gómez de Fuensalida con don Fernando también provenía desde su niñez, cuando Juan I lo nombró maestro de sus hijos Enrique y Fernando. Don Diego era natural de Toledo y pertenecía a la nobleza local. A finales del siglo xIV ya figura como bachiller en decretos y es posible que en 1403 ya fuera licenciado, año en el que ya era abad de Husillos y estuvo presente en la ceremonia de restitución de la obediencia castellana a Benedicto XIII en Santa María de Valladolid ${ }^{119}$. En 1404 ya era abad de Valladolid ${ }^{120}$ y en fechas indetermi-

114 FALCÓN PÉREZ, M. ${ }^{\text {a }}$ Isabel, Ordinaciones reales otorgadas a la ciudad de Zaragoza en el siglo XV. De Fernando I a Fernando II, Zaragoza, 2010.

115 RISCO, Manuel, España Sagrada..., p. 49.

116 DHEE, vol. III, p. 1870.

117 BNP., Ms. 216, fols. 89v-90r, publicado por GARCÍA, Michel, «El historiador en su taller...», n.ำ 17, p. 173. Es decir, respectivamente, Alfonso de Argüello, Diego Gómez de Fuensalida y Diego López de Stúñiga.

118 ACA., Cancillería, reg. 2408, fols. 84v-85r, (Perpiñán ¿1415, diciembre?).

119 Las referencias a este personaje, hasta el momento, proceden de VILLARROEL GONZÁLEZ, Óscar «Capilla y capellanes reales el servicio del rey en Castilla. La evolución en época de Juan II (1406-1454)", En la España Medieval, 31 (2008), pp. 309-356, y de su tesis doctoral titulada Las relaciones monarquía-Iglesia en época de Juan II de Castilla (1406-1454), 2 vols. Madrid, 2007. Tesis doctoral publicada en formato digital por la Universidad Complutense de Madrid. La licenciatura era en Decretos como tomo de EUBEL, Conradum, Hierarchía Catholica Mediaevi: ab anno 1198 usque ad annum 1431, vol. I, Münster, 1913, p. 539.

120 SANGRADOR VÍTORES, Matías, Historia de la Muy Noble y Leal Ciudad de Valladolid, desde su más remota antiguedad hasta la muerte de Fernando VII, Tomo II, Valladolid, 1851, p. 84. GOÑI GAZTAMBIDE, José, Los españoles en el Concilio de Constanza, Madrid, 1966, p. 5. 
nadas figura como capellán regio ${ }^{121}$ y como capellán mayor del infante don Fernando. Como tal aparece en 1410 en la Crónica de García de Santa María ${ }^{122}$, y en un documento fechado en el monasterio de Santa Inés de la Orden de Santa Clara en Sevilla el 12 de noviembre de ese mismo año, cuando figura como testigo de la donación que la abadesa y monjas del cenobio, conocedoras de que doña María Coronel había donado al infante el castillo de Capilla, en el arzobispado de Toledo, Burguillos cerca de la Higuera frontera de Portugal, Bolaños en tierra de Campos, Casarrubios del Monte y Aguilar de la Frontera en el obispado de Córdoba, la casa de Amión, el coto de Villamán, tierra de Pilla y tierra de Cornado en Galicia, con sus castillos, casas fuertes y llanas, aldeas, términos, montes, pastos, aguas, heredamientos, pechos y derechos y con los vecinos y moradores y vasallos de cualquier ley, estado o condición, con el mero mixto imperio y con la justicia civil y criminal, además de Montalbán, Mondéjar, Torija y Juncos, confirman la merced y le dan la posesión de las dichas villas, castillos, lugares, etc ${ }^{123}$. Su importancia en la vida política comienza precisamente este mismo 1410, cuando el regente castellano, infante don Fernando, le encomiende ir «... a Aragón e a Caragoça... al arçobispo de Caragoça e a los del reino de Aragón con sus cartas en que les envio rogar que pues el rey don Martin su tio era finado e Dios lo quiso llevar que les rogaba que fasta que viessen bien la justicia que quisiessen fazer rey con justicia que el tenia que por justicia le pertenecia suceder en los dichos reinos". Algunas de las razones de su elección las señala el cronista en el mismo párrafo cuando dice de él que «... era muy sabio e discreto... era letrado e sabía la justicia que el dicho infante tenía que la pudiese mostrar e les dezir su parezer» ${ }^{124}$. En efecto, todas esas cualidades y otras las pondrá de manifiesto a partir de ahora. En primer lugar, intentando hacer valer los derechos del infante de Castilla al trono de Aragón por medios tan diversos como los estrictamente diplomáticos y en segundo término atrayéndose la fidelidad de importantes linajes. Ejemplo de lo primero es su embajada ${ }^{125}$ y de lo segundo el acuerdo que firmó ante notario con García de Gurrea y con Lope de Gurrea el 7 de julio de 1411, en Illueca, señorío de Juan Martínez de Luna, por el que los dos primeros se comprometían a ayudar al infante en cualquier caso, hasta que fuese declarado rey en Aragón quien debía de serlo ${ }^{126}$, poco

121 VILLARROEL GONZÁLEZ, Óscar, “Capilla y capellanes...», pp. 309-356, da cuenta de sus orígenes, formación y cargos. El mismo autor lo cita en El rey y la iglesia castellana, pp. 487-488.

122 GARCÍA DE SANTA MARÍA, Álvar, Le parti inedite della: «Crónica de Juan Il» di Álvar García de Santa María, Edizione critica, introduzione e note a cura di Donatella Ferro, Venezia, 1972, p. 87.

123 RAH., M-10, fols. 89r-94r.

124 GARCÍA DE SANTA MARÍA, Álvar, Le parti inedite, p. 87. Casi en los mismos términos en GARCÍA DE SANTA MARÍA, Álvar, Crónica, (1982), p. 420.

125 GARCÍA DE SANTA MARÍA, Álvar, Le parti inedite, p. 71; GARCÍA DE SANTA MARÍA, Álvar, Crónica, (1982), p. 421. ZURITA, Jerónimo, Anales, pp. 99-100, lo nombra entre los embajadores de Juan II y del infante don Fernando enviados a la Corona de Aragón.

126 Acta Curiarum Regni Aragonum, Tomo VII, vol. I, nota 49, p. XXIV. SESMA MUÑOZ, José Ángel, El Interregno (1410-1412). Concordia y compromiso político en la Corona de Aragón, Zaragoza, 2011, p. 107, considera que el objetivo del acuerdo era no solo proteger las vidas y el territorio del gobernador y de su grupo, sino «... recoger a los seguidores del arzobispo que quedaban sin guía». Este autor, en nota al pie, proporciona la localización del documento en el Archivo de Protocolos de Zargoza. SESMA 
después del asesinato del arzobispo de Zaragoza. Su mediación entre los bandos de Zayas y Liñanes que se enfrentaban en Calatayud y cuyos jefes se inclinaban por el infante don Fernando y por el conde de Urgel, respectivamente, logrando una tregua ${ }^{127}$. Su intento por procurar tener como partidarios a los miembros de la Casa de Sesé, durante su estancia el Albalate, desde el cabeza del linaje Garci López de Sesé, a sus hijos, deudos y amigos: «... que eran muchos». El método fue atraérselos con la entrega de una encomienda de una de las Órdenes: Santiago, Calatrava o Alcántara, o con dinero en forma de rentas anuales o en forma de tierra para un determinado número de lanzas. La cuantía variaba de acuerdo con la condición y posición ocupada por cada uno dentro del propio linaje. Así, por ejemplo, a Garci López de Sesé se le prometió una encomienda, a elegir entre las de las órdenes señaladas, que rentase anualmente 800 florines, y mientras tardase en entregársela existía un compromiso de darle anualmente 500 florines; los miembros del linaje que ocupaban los escalones inferiores recibirían, por su parte, tierra para dos lanzas. La contraprestación a esta oferta, que realizó Diego Gómez de Fuensalida, conllevaba dos obligaciones por parte del linaje de los Sesé: el integrarse entre los favorables de don Fernando y el devolver a varios capitanes castellanos que tenían presos ${ }^{128}$. También prestó apoyo militar junto con varios capitanes castellanos a los parlamentarios que estaban convocados en Alcañiz, ya que «... don Antón de Luna con los de su bando e con los que tenían la opinión del conde de Urgel, e sus gentes, se avían puesto por los caminos para les fazer daño e fazer que no fuesen al parlamento de Alcañiz» ${ }^{129}$. Fue precisamente en Alcañiz donde pasó a residir ${ }^{130}$ y donde desempeñó de forma magistral el cometido encomendado, asistiendo de forma ordinaria a las reuniones, informando del derecho que el infante don Fernando tenía a la sucesión, tanto a los presidentes como a las congregaciones de los estados de la Corona, o visitando a Benedicto XIII, en suma «... informado y procurando todo lo que convenía al servicio del infante» 131 . De ahí que poco tiempo después lo veamos ante al parlamento de Alcañiz, el 2 de enero de 1412, donde entregó unos capítulos escritos de manos de don Jaime de Urgel y una carta del rey de Granada, para denunciar y mostrar los tratos que les vincu-

MUÑOZ, José Ángel, y LALIENA CORBERA, Carlos, «Las élites políticas de Aragón durante el Interregno y el Compromiso de Caspe", La Corona de Aragón en el centro de su historia 1208-1458. El Interregno y el Compromiso de Caspe, J. Ángel Sesma Muñoz (Coordinador), Zaragoza, 2012, pp. 165-190 [p. 187].

127 GARCÍA DE SANTA MARÍA, Álvar, Le parti inedite, p. 89; GARCÍA DE SANTA MARÍA, Álvar, Crónica, (1982), pp. 421-422; ZURITA, Jerónimo, Anales, p. 51.

128 ZURITA, Jerónimo, Anales, p. 161. Los ofrecimientos que hizo y el nombre de los capitanes castellanos se detallan en CoDoln. ACA, Tomo X, pp. 403-405. Este hecho y las denuncias de los representantes del conde de Urgel en las Cortes de Tortosa, el 24 de noviembre de 1411, se pueden ver en Cortes de los Antiguos Reinos de Aragón y de Valencia y Principado de Cataluña, RAH, Madrid, vol. IX, 1905, pp. 102-103 y 10-11, respectivamente.

129 PÉREZ DE GUZMÁN, Fernán, Crónica, p. 341; GARCÍA DE SANTA MARÍA, Álvar, Crónica, (1982), pp. 424. En términos parecidos ZURITA, Jerónimo, Anales, p. 114.

${ }_{130}$ GOÑI GAZTAMBIDE, José, Los españoles, p. 6, señala que desde el 2 de septiembre de 1411 solía residir en aquella villa.

131 ZURITA, Jerónimo, Anales, p. 187. 
laban, así como la ruptura de la tregua existente entre Castilla y Granada por el apoyo militar de los granadinos.

Primo, que aie a fer guerra a son adversari de tot son poder e que de son tresor valegar al dit son amich per a soldadar mil bacinets e mil pillarts pagats por mig ayn, que muntarian a CCLXX mil, d'quest nombre si fer nos pot devall de poch en poch. E que faça guerra ab tot son poder e sforç lo rey de Granada contra lo infant de Castella e tota sa terra, e lo dit senyor lo fara de part deça ab tot son sforç contra la dita terra del dit infant ${ }^{132}$.

En la citada asamblea le contestó Berenguer de Bardají «... concluyendo... con una muy determinada declaración: que en caso que los otros parlamentos no quisiesen libremente entender en la causa de la sucesión, los del reino de Aragón y el parlamento dél usarían de su preeminencia y libertad así como aquéllos que eran cabeza de los otros reinos y tierras de la corona real» ${ }^{133}$.

Tras la elección de don Fernando como rey en Caspe su importancia y la confianza que el monarca tenía en él se revela en los hechos en que tomó parte así, por ejemplo, figura como testigo en la presentación y juramento de los tres delegados - Juan de Subirats, Berenguer de Bardají y Francisco Sarçuela- encargados de averiguar la situación en la que se encontraban los bienes patrimoniales de la Corona de Aragón en los comienzos del reinado de Fernando $\mathrm{I}^{134}$, intervino en las Cortes de Zaragoza de 1412, donde figura como consejero real ${ }^{135}$ y fue designado uno de los tratadores que tenían que adoptar ciertas medidas de gobierno para Aragón, junto con Francés de Aranda, Gil Ruiz de Lihori y Berenguer de Bardají ${ }^{136}$. También aparece entre los firmantes de la carta de procuración de la corte a favor de Ramón de Casaldáliga, facultándole a vender censales sobre el general del reino ${ }^{137}$, entrevistándose con el conde de Urgel y más tarde tratando con sus embajadores sobre una posible boda entre una hija del conde con el infante don Enri-

132 Acta Curiarum Regni Aragonum, Tomo VII, vol. I, p. XXXVIII. El documento en las pp. 261-262. ZURITA, Jerónimo, Anales, pp. 186-187.

${ }_{133}$ Acta Curiarum Regni Aragonum, Tomo VII, vol. I, p. XXXVIII. El documento en las pp. 261-262. ZURITA, Jerónimo, Anales, pp. 186-187.

134 GALLOSTRA VENDRELL, Francisca, Rentas reales de Aragón de la época de Fernando I (14121416), CODOIN. ACA, vol. XLVII, Madrid-Barcelona, 1977, p. 15.

135 ZURITA, Jerónimo, Anales, p. 389. También destaca este hecho SARASA SÁNCHEZ, Esteban, Aragón en el reinado de Fernando I (1412-1416). Gobierno y Administración. Constitución Política. Hacienda Real, Zaragoza, 1986, pp. 72-73. NAVARRO ESPINACH, Germán, "Consejeros influyentes y personas de confianza en el entorno cortesano de los reyes de Aragón (siglos XIII-XV)", La Corona de Aragón en el centro de su Historia 1208-1458. La monarquía aragonesa y los reinos de la Corona de Aragón, Zaragoza y Monzón 1 al 4 de diciembre de 2008, Ángel Sesma Muñoz (Director científico), Zaragoza, 2009, pp. 129-179 [p. 163].

136 CANELLAS LÓPEZ, Ángel, «La instauración de los Trastámara en Aragón», Cuadernos de Historia Jerónimo Zurita, 4-5 (1953), pp. 19-38 [nota 55, p. 36].

137 Cortes del reinado de Fernando I. Cortes de Zaragoza 1412. Cortes de Zaragoza 1413-1414, en Acta Curiarum regni Aragonum, Tomo VIII, Edición a cargo de Germán Navarro Espinach, Zaragoza, 2009, pp. 195-205. 
que de Aragón ${ }^{138}$, o asistiendo a la entrevista entre Benedicto XIII y Fernando I en Tortosa, el 21 de noviembre del mismo $1412^{139}$. A comienzos de 1413 , se le designó maestre racional respecto a Aragón ${ }^{140}$, el 23 de febrero, y, sin duda, a instancia del rey de Aragón, fue investido con la mitra de Zamora, sede de la que fue obispo hasta $1424{ }^{141}$, aunque tardó cerca de un año en recibir la consagración espiscopal ${ }^{142}$. Diego Gómez de Fuensalida presenció en Barcelona el préstamo monetario que Bernat de Gualbes, Sperandeu Cardona y Antonio Tallander, -Mosén Borrahicieron al monarca para el asedio a Balaguer ${ }^{143}$, con fecha 23 de mayo, y a mediados del mismo año dispuso, junto a Pedro Jiménez de Urrea y Juan de Bardají, el envío de gente de armas de Castilla a la ciudad de Huesca, con el fin de reforzar la frontera por donde entraban compañías armadas de gascones y de ingleses al mando de don Antonio de Luna ${ }^{144}$, poco después tuvo el protagonismo ya expuesto en el cerco a Balaguer. El 11 de febrero de 1414 asistió a la coronación de don Fernando en Zaragoza ${ }^{145}$, el 18 de mayo entregó a Julián de Loba, receptor de la Cámara Apostólica, cien florines del cuño de Aragón ${ }^{146}$, y fue uno de los miembros del Consejo real nombrados para asistir a las vistas entre Fernando I de Aragón y Benedicto XIII en Morella ${ }^{147}$. El 10 de octubre de ese mismo año recibió en préstamo qunientos florines de Aragón, por mano de Joan Teixidor, canónigo y subcolector de Barcelona, cantidad que sus procuradores devolvieron a Julián de Loba ${ }^{148}$. $Y$ ese mismo mes de octubre fue elegido miembro de la embajada que, junto con

138 PÉREZ DE GUZMÁN, Fernán, Crónica, pp. 346-347. ZURITA, Jerónimo, Anales, p. 299, la primera cuestión, la segunda en p. 306. Según señala Zurita en esta última página don Diego influyó en el monarca para que viese, junto con los de su consejo, la posibilidad de casar a uno de sus hijos con una hija del conde de Urgel. Véase también CARBÓ, Laura, «La relación competitiva entre Fernando I de Aragón y el Conde de Urgel. El fracaso de la negociación y el enfrentamiento armado (1410-1413)», Estudios de Historia de España, vol. XII/1 (2010), pp. 73-91 [p. 84].

139 GOÑI GAZTAMBIDE, José, Los españoles, p. 7.

140 SARASA SÁNCHEZ, Esteban, Aragón en el reinado, p. 94, destaca este nombramiento como excepcional, ya que Aragón no tuvo un maestre racional exclusivo hasta finales del siglo XV, y lo considera meramente honorífico. En cualquier caso, cree que el obispo de Zamora fue el principal consejero de Fernando I, al intervenir en todas las ocasiones decisivas de su reinado.

141 EUBEL, Conrad, Hierarchía Catholica Mediaevi, p. 539. DHEE, vol. IV, Madrid, 1975, p. 2799.

142 GOÑI GAZTAMBIDE, José, Los españoles, p. 7.

143 BOFARULL Y DE SARTORIO, Manuel de, Tres cartas autógrafas e inéditas de Antonio Tallander Mossén Borra maestro de los albardanes de D. Fernando de Antequera y algunos documentos desconocidos relativos al mismo personaje, Barcelona, 1895, n. 4, pp. 59-63, donde figura como «Consiliarius et Capellanus maior». GOÑI GAZTAMBIDE, José, Los españoles, p. 7.

144 ZURITA, Jerónimo, Anales, p. 335. En fecha indeterminada el rey don Fernando lo autorizó para entrar en tratos con don Antonio de Luna, como tomo de SANCHO IZQUIERDO, Miguel, «Ensayo de una biografía de Don Antonio de Luna y de su influencia en el Compromiso de Caspe», Revista de Archivos, Bibliotecas y Museos, Tercera época. Año XVIII, tomo XXX (1914), pp. 107-115; 265-282; $453-464$ [p. 462].

145 PÉREZ DE GUZMÁN, Fernán, Crónica, p. 385.

146 BAUCELLS I REIG, Josep, El fons, n.ำ 396, p. 197.

147 ZURITA, Jerónimo, Anales, p. 404. Antal de ALDASY, «Les rapports de Sigismond avec le royaume d'Aragón", Estudis Universitaris Catalans, vol. XX (1935), pp. 1-49 [p. 13], le hace enviado del rey de Castilla. Se sabe que formó parte de la comisión que se nombró para el examen de las tres cuestiones que propuso Benedicto XIII, como señala SUÁREZ FERNÁNDEZ, Luis, Castilla, el Cisma y la Crisis Conciliar (1378-1440), Madrid, 1960, nota 19, p. 70.

148 BAUCELLS I REIG, Josep, El fons, n. 409, p. 201. 
Juan Fernández de Híjar y con Pedro Falchs, tenía como misión concertar una entrevista con Ottobono de Bellonis e impedir la inminente reunión del concilio ${ }^{149}$. «omose por resolución que se enviasen sobre ello embajadores a Sigismundo y a los que estaban ya congregados en el Concilio de Constancia. $Y$ de la parte del rey de Aragón se nombraron a Diego Gómez de Fuensalida obispo de Zamora, don Juan Fernández señor de ljar y Pedro de Falchs muy famoso letrado» ${ }^{150}$. Esa embajada tuvo entre otras escalas Montpellier, donde estarían entre el 29 de octubre y el 3 de noviembre, y Lausana, donde llegaron el 7 de diciembre y donde escribieron una carta pidiendo dinero ${ }^{151}$, antes de llegar a Constanza, donde pretendían pasar la Navidad y donde no quisieron aceptar el aposento que se les asignó, por lo que se detuvieron en Zaffusa ${ }^{152}$.

El día 8 del mes de enero de 1415 estos embajadores entraron en la ciudad de Constanza, sin ningún recibimiento, ya que iban junto con los que el papa Benedicto XIII envió, alojándose en un monasterio «Y enviándose a excusar con esto el emperador, respondió el obispo de Zamora que el rey de Aragón a donde quiera era muy honrado, y no había menester más honra de la que Dios le había dado en el mundo, y que sus embajadores a donde quiera que estuviesen eran honrados por él» ${ }^{153}$. El emperador recibió a los embajadores del rey de Aragón en el monasterio de San Pedro de Kreuzlingen el 13 de enero y el obispo de Zamora manifestó su deseo de entrevistarse en secreto con el emperador. La negativa del emperador Segismundo al contestarle que si tenía algo que decir debía exponerlo en presencia del Concilio, hizo intervenir a don Diego, que tres días más tarde escribió a don Fernando sobre el estado en que se encontraban las negociaciones ${ }^{154}$ El 21 de marzo suscribe la carta junto a los otros dos embajadores aragoneses en Constanza dando cuenta al rey de Aragón de la huída del papa Juan XXIII de la ciudad y pidiéndole dinero ${ }^{155}$. De este viaje a Constanza y de los gastos que Diego Gómez de Fuensalida hizo en ella «... por la cuestión del Cisma de la Iglesia» existe constancia documental ${ }^{156}$.

En Constanza permanecieron los embajadores y, por lo tanto, Diego Gómez de Fuensalida, hasta el 27 de marzo en que emprendieron el viaje de regreso,

149 SUÁREZ FERNÁNDEZ, Luis, Los Trastámara de Castilla y Aragón en el siglo XV (1410-1474), en Historia de España de Menéndez Pidal, Tomo XV, Madrid, 1970, pp. 1-318 [56].

151 GOÑI GAZTAMBIDE, José, Los españoles, p. 8.

152 ZURITA, Jerónimo, Anales, p. 425. GOÑI GAZTAMBIDE, José, Los españoles, p. 8, señala que pararon primero en Schaffhausen y después en Stein, antes de llegar a Constanza.

153 ZURITA, Jerónimo, Anales, pp. 425-426. GOÑI GAZTAMBIDE, José, Los españoles, p. 8.

154 GOÑI GAZTAMBIDE, José, Los españoles, pp. 8-9.

155 BOFARULL Y SANS, Francisco de, Felipe de Malla y el Concilio de Constanza. Estudio históricobiográfico. Documentos justificativos, y correspondencia diplomática de los embajadores aragoneses, Gerona, 1882, nota 1, pp. 47-48. GOÑI GAZTAMBIDE, José, Los españoles, p. 10.

156 ACA., Real Patrimonio, reg. 2662, fol. LXXXIV, en SARASA SÁNCHEZ, Esteban, Aragón en el reinado, pp. 140 y 202. Orden de pago fechada en Valencia el 15 de agosto de 1415, por la que se le debían entregar 100 florines, en pago de los 407 florines, 5 sueldos y 7 dineros barceloneses que había gastado en Constanza. 
llegando hasta Banyols, a quince o dieciséis leguas de Montpellier, donde recibieron carta del monarca pidiendo al obispo de Zamora a Pere Falchs y al secretario de la embajada su vuelta a Constanza, aunque el 2 de mayo el monarca les dio una contraorden para que regresasen inmediatamente ${ }^{157}$. El 15 y el 25 de junio estaba en presencia de Benedicto XIII y el 15 de julio don Fernando mandó que se le abonasen 100 florines por su embajada ${ }^{158}$. En fecha posterior, pero en este mismo año, el rey de Castilla lo nombró embajador para asistir a las vistas de Perpiñán, entre Benedicto XIII, Segismundo de Luxemburgo y Fernando I de Aragón ${ }^{159}$, aunque sin duda también fue como consejero del rey de Aragón ${ }^{160}$. Esto último y las dificultades por las que pasaba la conferencia hicieron que el infante don Alfonso, en nombre de su padre, gravemente enfermo, solicitase a Benedicto XIII el obispado de Segovia para Gómez de Fuensalida, aunque no lo consiguió, era el 23 de noviembre de $1415^{161}$.

Diego Gómez de Fuensalida asistió al Concilio de Constanza, pero no formó parte ni de la embajada castellana ni de la aragonesa ${ }^{162}$, y tuvo una escasa intervención inicial. Muerto su mentor, que intervino en su promoción eclesiástica y le hizo alguna concesión ${ }^{163}$, perdió el protagonismo que había tenido y no fue hasta varios años después, y ya en Castilla, cuando regresó al primer plano de la vida política $^{164}$.

\section{PAGOS ORDENADOS POR EL OBISPO DE ZAMORA EN RELACIÓN CON EL ASEDIO A BALAGUER}

La importancia que cada uno de estos tres prelados tuvo en las campañas bélicas de don Fernando y su actuación anterior y posterior a esos servicios, ha dejado escasas huellas desde el punto de vista económico, como el pago a don Sancho de Rojas por los hombres que tuvo a su costa en 1407, no así por los que dispuso en 1410, y poco más. Pero sí hay constancia documental de pagos realizados a instancias de don Diego Gómez de Fuensalida relacionados con el asedio y conquista de Balaguer en 1413, como se conoce por el documento ya señalado

157 GOÑI GAZTAMBIDE, José, Los españoles, pp. 11-12.

158 GOÑI GAZTAMBIDE, José, Los españoles, p. 12.

159 El documento completo en ZURITA, Jerónimo, Anales, pp. 473-479, donde figura como oídor de la Audiencia.

160 Como señala GOÑI GAZTAMBIDE, José, Los españoles, p. 14

161 GOÑI GAZTAMBIDE, José, Los españoles, p. 14.

162 TROCA PEREIRA, Reina Marisol, Discursos dos embaixadores portugueses no concilio de Constança, http://www.ehumanista.ucsb.edu/projects/Monographs\%202/mongraphs/perea.pdf, consultado el 21 de septiembre de 2013.

${ }_{163}$ Me refiero en este último caso a la concesión del feudo e iglesia de Grustán, en las inmediaciónes de Graus, que fue confiscada a Jaime de Urgel, aunque desconozco el momento exacto en que se le otorgó. IGLESIAS COSTA, Manuel, Historia del Condado de Ribagorza, Huesca, 2001, p. 460.

164 GOÑI GAZTAMBIDE, José, Los españoles, p. 14. En abril de 1417 parece ser que estaba en Constanza, como tomo de BELTRÁN DE HEREDIA, Vicente, Cartulario, nota 6, p. 253. 
perteneciente al ejercicio del año 1413-1414, procedente del Archivo de la Corona de Aragón, Real Patrimonio, reg. 2660, fols. XLv-LXXXv.

En dicho documento se recogen aproximadamente cincuenta órdenes de pago efectuadas por mandato expreso del entonces obispo de Zamora, don Diego Gómez de Fuensalida. En esas órdenes se pueden distinguir varias partidas, la correspondiente a satisfacer el importe de las máquinas y las armas empleadas para el asedio y asalto de la ciudad, los pagos derivados del transporte de material, los del sueldo de las tropas, emisarios, correos, espías, etc, y los ocasionados por los mandamientos judiciales para ocupar los bienes de los rebeldes en Aragón ${ }^{165}$, aparte de otros que no tienen relación directa con los anteriores, como pueden ser el cobro de rentas de algunas aljamas o ciertas demandas para la coronación de don Fernando.

Pues bien, la cuantificación de esas aproximadamente cincuenta órdenes de pago realizadas por mandato de don Diego Gómez de Fuensalida se eleva a:

- 350 sueldos, sin especificar.

-12.286 sueldos barceloneses.

- 4.453 sueldos y 38 dineros jaqueses.

- 10.413 florines de Aragón.

Si se tiene en cuenta que los gastos totales del ejercicio 1413-1414 fueron:

- 14.884 sueldos barceloneses.

- 10.588 sueldos jaqueses.

- 30.468 florines y medio de Aragón ${ }^{166}$.

Los 12.286 sueldos barceloneses, librados por orden de don Diego, representarían aproximadamente el $82,54 \%$ de los pagos realizados con esa moneda, los 4.453 sueldos jaqueses el 42,05\% y los 10.413 florines de Aragón el 34,17\%. La mayor partida de gastos registrada es la del sueldo de las tropas, emisarios, correos, espías, etc, y la menor la derivada de los mandamientos para ocupar los bienes de los rebeldes a la autoridad del monarca. De todo ello se puede deducir la importancia de las cantidades satisfechas por orden del obispo de Zamora, aunque en algunos casos no se han tenido en cuenta las cantidades totales, sino las libradas en un cierto momento, quedando otras pendientes de pago. Importancia evidente también si se agrupan las órdenes de acuerdo con las partidas señaladas $^{167}$, de las que en el Apéndice se hace una selección.

165 Para esta clasificación me baso en SARASA SÁNCHEZ, Esteban, Aragón en el reinado, pp. 137-138.

166 Estos últimos datos proceden de SARASA SÁNCHEZ, Esteban, Aragón en el reinado, p. 138.

167 Los documentos que transcribo en parte a continuación no están por orden cronológico, sino de acuerdo con su ubicación en el documento original, a lo que hay que sumar la clasificación que se ha 


\section{CONCLUSIÓN}

Así pues, a la vista de lo expuesto y en breve síntesis podemos concluir señalando:

- La importancia de los eclesiásticos castellanos en las campañas militares de don Fernando, desde puntos de vista tan diferentes como el propiamente militar, el económico, el moral o el logístico.

- El que los tres altos dignatarios pertenecieran al círculo más allegado a don Fernando desde su niñez o juventud.

- El que los tres hubiesen dado muestras de competencia en diferentes encargos anteriores a las campañas militares.

- El distinto carácter de las ayudas de Sancho de Rojas, Alfonso de Argüello y Diego Gómez de Fuensalida.

- Las grandes atribuciones y el margen de actuación con que contó Diego Gómez de Fuensalida en relación con el cerco a Balaguer.

- La constatación de Zaragoza y Barcelona como importantes centros de aprovisionamiento de todo tipo en relación con el sitio a Balaguer.

- El afianzamiento de Diego Gómez de Fuensalida como consejero y diplomático.

- La posible vinculación entre la promoción eclesiástica de Sancho de Rojas y de Diego Gómez de Fuensalida con sus recientes servicios militares.

\section{APÉNDICE}

a) Gastos de las máquinas empleadas para el asalto y armas

- 23 de marzo 1414. Item dio de mandamiento del dito senyor obispo a Guillén Pardo repostero de casa del senyor rey los quales el dito senyor obispo le mandó dar como fue dela ciudat de Caragoza al sitio de Balaguer con el trabuco engenio e otras castellerías que leuauan al senyor rey e aquellos le fueron dados para adobar los caminos e aplanar los pasos por do auían

hecho de ellos. Cada uno de estos fragmentos va precedido por la fecha y finaliza con la foliación y la cantidad satisfecha. 
de passar los carros que leuauan los ditos engenios trabuqos e otras castellerías..., fol. XLIv. (20 florines) ${ }^{168}$.

- 6 de octubre 1413. Item dio de mandamiento e hordenación del dito senyor obispo a Martín García de Paredes de casa de la senyora reyna daragón agora bien auenturadamente regnante hestante enla ciudat de Caragoca los quales el dito senyor obispo le mandó dar pora missión de un biage e ¿fuga? dela ciudat de Caragoca al sitio de Balaguer con ciertas asemillas que lieve cargadas de ballestas de trono e de cajones de biratones e otras artellerías..., fol. XLIIlv. (100 sueldos jaqueses).

- 7 de octubre 1413. Item dio de mandamiento del dito senyor obispo a Antón López regent la botiga del honorat Anthonio Rubio mercader enla ciudat de Caragoca los quales le ran deuidos por precio de III ballestas de torno e las II de cinfonia las quales del fueron comparadas e aquellas fueron enuiadas al senyor rey al sitio de Balaguer..., fol. XLIVr. (22 florines).

- 8 de octubre 1413. Item dio de mandamiento del dito senyor obispo a Jaime Casa Franca mercader hestant enla ciudat de Caragoca los quales li heran deuidos por precio de dos ballestas de torno que dél fueron compradas e aquellas fueron enuiadas al senyor rey al sitio de Balaguer..., fol. XLIVv. (30 florines).

- 8 de octubre 1413. Item dio de mandamiento e hordenación del dito senyor obispo a... vecinos dela ciudat de Caragoca e aquellos porel dito Ffrancesp Ferriol li mandó dar a Bonafós dela Cauallería... los quales li fueron dados liu/rados e pagados por loguero suyo e de IIII hombres que fueron conel en acompañar las carretas que leuaron el trabuquo e engenyo que partió dela ciudat de Caragoca al sitio de Balaguer al senyor rey e por endicar los passos e caminos por do las ditas carretas hauían de pasar..., fols. XLVr-v. (16 florines).

- 13 de octubre 1413. Item dio de mandamiento e hordenación del dito senyor obispo a Antón de Cabirán mercadero uecino dela ciudat de Caragoca los quales li herán deuidos por L paveses de barrera que dél fueron com-

168 Los números 1, 2, 3, 4, 6, 7, 8, 9, 11, 12, 13, 14, 17, 18, 20, 21, 22, 23, 24, 25, 26, 28, 29, 30, 31, 33, 35 y 36, cuentan con un breve regesto en la obra de SARASA SÁNCHEZ, Esteban, Aragón en el reinado, pp. 164-168. 
prados a rassón de I florín y medio por pavés e aquellos de mandamiento del dito senyor obispo fueron enviados al senyor rey al sitio de Balaguer enla qual compra enteruino el honorable Nicholau de Biota escriuano de ración de casa del dito senyor..., fol. XLVv. (75 florines).

\section{7}

- 21 de octubre 1413. Item dio de mandamiento del dito senyor obispo por la manera de yuso scripta a Gil de Lliretas vezino dela ciudat de Caragoca la quantía de sou pesada la qual li era deuida por rasón de XXII dineros e un quart e poco más de cuerdas de canyamo que del fueron compradas de mandamiento del dito senyor obispo e aquellas fueron enuiadas al senyor rey al sitio de Balaguer..., fol. XLIXr. (445 sueldos y 6 dineros jaqueses).

8

- s/d de noviembre 1413. Item dio de mandamiento del dito senyor obispo a Johan Maldonado uecino del lugar de Alfocea los quales li heran deuidos por leuar dela ciudat de Caragoca al sitio de Balaguer do el senyor rey hera una percha del engenyo que leuaron IIII carros con el trabuquo de Trasmoz con distintas castellerías e con cuerdas de canyamo que fueron cargadas dentro enla ciudad de Caragoca al dito sitio de Balaguer XVIII días de que el hauía delas dos carretas que leuauan la percha del engenyo a razón de IX sueldo por cada una carreta por día e delas dos carretas qui leuauan el trabuquo e cuerdas e otras artellerías a razón de VII sueldos por cada una carreta por día que montan DXXVI sueldos jaqueses et por un día que fizieron estadía en Balaguer las ditas carretas XX sueldos e porel retraso que fizieron enel sitio de Balaguer a Caragoca houieron a razón de IIII sueldos por cascuna carreta por cada día enel qual retraso stuuieron seys días enla benida que montan LXXXX VI sueldos..., fol. Lr. (692 sueldos jaqueses).

- 3 marzo 1414. Item dio de mandamiento del dito senyor obispo a mosén Ramón de Mur cauallero consellero del senyor rey e bayle general del regno daragó los quales li heran deuidos por precio de dos ballestas que del de mandamiento del dito senyor obispo fueron compradas e aquellas el dito senyor obispo enuió al sitio de Balaguer..., fol LXVr. (12 florines).

\section{b) Gastos derivados del transporte de material}

- 6 octubre 1413. Item dio de mandamiento del dito senyor obispo a Pedro Casa Nueva... de dos asemilas suyas que fueron cargadas dela ciudat 
de Caragoca al sitio de Balaguer con ballestas e otras artellerías que de mandamiento del dito senyor leuauan al senyor rey... III florines por cada cargamento..., fol. XLIIIv. (6 florines).

- 6 enero 1414. Item dio a Martín Dalcanyz carretón uezino dela ciudat de Caragoca como procurador de Johan de Ezmilla carretón uezino dela dita ciudat los quales li fueron dados de mandamiento del dito senyor obispo en paga porél préstamo de $\mathrm{V}$ pares de bueyes questuuieron enel sitio de Balaguer con sus carros ciertos días..., fol. LVv. (5 florines).

12

- 21 abril 1414. Item dio a mossén Pardo la Casta merino dela ciudat de Caragoca los quales el senyor obispo li mandó dar por precio de un carro que del dito mossén Pardo fue comprado e aquell fue enuiado ensemble con otros al senyor rey al sitio de Balaguer..., fol. LXXIIIr. (8 florines).

c) Sueldo de las tropas, emisarios, correos, espías

13

- s/f. Item dio de mandamiento del dito senyor obispo Adalfonso de Fuent Sallida scudero los quales el dito senyor le mandó dar acomplimiento delas expenssas que hauían fetas enel camino que fue al sitio de Balaguer..., fol. XLIv. (8 florines).

14

- 2 octubre 1413. Item dio de mandamiento e hordenación del dito senyor obispo a Johan de Miranda castellano e a Pedro Nauarro del regno de Nauarra los quales de mandamiento del dito senyor obispo fueron por espías a Bayona a Lorón por saber e sentir si se amassauan gent darmas ni si don Anthon de Luna hera entre daquellas partidas..., fol. XLIlv. (8 florines).

15

- 2 octubre 1413. Item dio de mandamiento el dito senyor obispo a Miguel ¿Confín? ¿bordador? hestante enla ciudat de Caragoça los quales le heran deuidos por precio de III ballestas que dél fueron compradas para enviarlas al senyor rey al sitio de Balaguer..., fol. XLIIIr. (18 florines).

16

- 23 octubre 1413. Item dio de mandamiento e hordenación del dito senyor obispo a don Noha Chiniello judío de la uilla de Hixar... por pagar el sueldo 
al dicho don Johan Dixar de dos meses ala gente darmas que tenía en servicio del senyor rey enel sitio de Balaguer..., fol. XLIIIr. (5 florines).

- 6 octubre 1413. Item dio a Farach e ha Ffamet moros de Torrellas hestantes enel lugar de Torrellas de mandamiento del dito senyor obispo los quales el dito senyor mandó hir al senyor rey al sitio de Balaguer por seruir allá un mes de ballesteros e punteros e por obrar hierros de biratones a rasón de III sueldos jaqueses lo dia por cadauno dellos..., fol. XLIVr. 180 sueldos jaqueses.

- 23 octubre 1413. Item dio de mandamiento e hordenación del dito senyor obispo a Pedro Cuchielles ciudadano dela ciudat de Taracona la cantidat que fuese posada porel acumplimiento del sueldo de LVI ballesteros e dos hombres acauallo que los guiauan... dela dita ciudat de Taracona al sitio de Balaguer de arqueros e ballesteros quel dito senyor rey con gran justicia demandaua que fuesen al dito sitio e que fuesen... los LVI a los quales fue acorrido... enla dita ciudat por el sueldo de XV días de mandamiento del dito senyor obispo a razón de III sueldos jaqueses que por cadauno delos ditos ballesteros por día..., fol. XLVIr. (20 sueldos jaqueses y 71 florines).

19

- 18 noviembre 1413. Item dio de mandamiento e hordenación del dito senyor obispo a Danthon Plegrín hospet de correus enla ciudat de Caragoca los quales ell aquellos hauía bistraydos dados en pagados a diuersos correus que fueron en diuersas partes de mandamiento del dito senyor obispo por afers delos negocios de la cort del senyor rey..., fol. Lv. (785 sueldos jaqueses y 53 florines).

\section{0}

- 20 noviembre 1413. Item dio de mandamiento del dito senyor obispo a Pero Nauares hestat enla ciudat de Huescha el qual de mandamiento e hordenación del dito senyor fue por espía a Bordeu e aotras partes enla rebellión o guerra que don Jayme Durgell fazía contra el senyor rey..., fol. LIv. (6 florines).

\section{1}

- 17 diciembre 1413. Item dio de mandamiento e hordenación del dito senyor a Andrés de Salua Tierra scudero los quales el dito senyor obispo li mandó dar por las ¿albrixias? que él li trayo del sito de Balaguer como el comte durgell se era metido sueltament en poder del senyor rey..., fol. LIIIr. (15 florines). 


\section{2}

- 8 febrero 1413. Item dio de mandamiento e hordenación del senyor rey e del senyor obispo de Camora a mossén Gil Ruyz de Lihori consellero e camarlench del dito senyor rey por acorrimiento de $C$ hombres acauallo armados con los quales a seruido al dito senyor rey enel dito regno enla execución quel dito senyor ha feta contra don Jayme durgell..., fols. LXVLXIv. (Un pago de 3.000 florines y otro de 900).

\section{3}

- 9 febrero 1413. Item dio de mandamiento e hordenación del dito senyor obispo a Auihuelo Castellano dela casa del senyor rey los quales el dito senyor obispo li mandó dar grosament por las albixaras que trayo al dito senyor obispo como el conde durgell se era metido sueltament en poder del senyor rey..., fol. LXIIv. (10 florines).

\section{4}

- 4 de marzo de 1414. Item dio de mandamiento del dito senyor obispo a mosén Suero de Naua cauallero e talladorero mayor del senyor rey en paga por razón de aquellos DCC florines doro a él restantes pagar por la cort del senyor rey de aquellos MXXI florines que por la dita cort li heran deuidos por razón del sueldo de cierta gent darmas e de píe que él hauía tenido en seruicio del dito senyor rey enla guerra de don Jayme durgell..., fol. LXVr. (530 florines).

\section{5}

- 5 de marzo 1414. Item dio de mandamiento e hordenación del dito senyor obispo a micer Johan de Funes dotor en leyes hestant enla ciudat de Caragoca los quales li heran deuidos porel sueldo de VI rocines con los quales el honorable micer Johan de Funes dotor en leyes e consellero del dito senyor ha seruido al dito senyor rey II meses enla execución quel dito senyor ha feta contra don Jayme durgell e sus cohaderentes..., fol. LXVIIV. (180 florines).

\section{6}

- 21 de abril 1414. Item dio de mandamiento del dito senyor obispo a Pedro de Mont Cler barbero dela ciudat de Caragoca el qual de mandamiento del dito senyor obispo fue dela ciudat de Caragoca al castiello de Loharre por espía enel mes de/ setiembre más cerqua passado por saber e sentir do Antón de Luna si hera enel castiello de Loharre..., fols. LXXIIv-LXXIIIr. (6 florines).

\section{7}

- $s / f$. Item dio a Johan de Çamora correu que fue de Caragoca a Leyda enel mes de nouiembre más cerqua passado con letras del senyor obispo que leuó al senyor rey e fue por auantalla que le fue feto..., fol. LXXIIIr. (1 florín). 
d) Mandamientos judiciales para ocupar bienes de los rebeldes

- 10 octubre 1413. Item dio de mandamiento del dito senyor obispo a Pero Ferrer pintor hestant enla ciudat de Caragoca los quales le heran deuidos por salario de $\mathrm{C}$ pendones reales quel dito senyor obispo mandó fazer por ponerlos enlas heredades bienes casas e castiellos delos rebeldes que prendían e ocupauan amanos dela cort del dito senyor rey..., fol. XLIVV. (55 sueldos jaqueses).

- 18 noviembre 1413. Item dio de mandamiento del dito senyor obispo a Pero Hortiz de Zaualza hestant enla ciudat de Caragoca los quales el dito senyor li mandó dar por traballos que hauían sotenidos en Hortés Johán Depila portero del senyor rey comisario subdelegado porel dito senyor aprender $\mathrm{e}$ ocupar los bienes delos rebelles dalla Ebro e enlas montanyas de Jaca..., fol. LIr. (6 florines).

- 4 ¿noviembre? 1413. Item dio de mandamiento e hordenación del dito senyor obispo a Johan de Epila portero del senyor rey hestant en Caragoca los quales el dito senyor li mandó dar por salario de XXXVIII días que él como comissario subdelegado del dito senyor obispo fue dalla el río de Ebro... et enlas montanyas de Jaca por prender e occupar amanos dela cort del senyor rey los bienes delos rebelles..., fol. Lllr. (265 sueldos jaqueses).

\section{1}

- 24 diciembre 1413. Item dio de mandamiento e hordenación del dito senyor obispo a Bernat Plaza notario los quales li heran deuidos por salario de XVIII días quél mo notario fue con Estheuan Caragocano portero del senyor rey comissario subdelegado por el dito senyor obispo aprender e occupar amanos del dito senyor rey los bienes delos rebelles alos lugares de Quart a Uilla Nueua de Burgacut ala uilla dalagón e alos lugares del río dexalón e del río de Borga et... yeran deuidos CXC sueldos dis jaqueses por salario de XXXVIII días que vaquó como notario que fue dallá el río de Ebro ala uillas de Exea a Tahust a layana a uncastiello a Sos a Gordún e a otros lugares de la montanya de Jaqua con Johan Depila portero del dito senyor rey comissalis subdelegado del dito senyor obispo a prender e occupar los bienes delos rebelles en las ditas uillas e lugares amanos dela cort del senyor rey..., fol. LII. (280 sueldos jaqueses). 
- 30 diciembre 1414. Item dio de mandamiento del dito senyor obispo a Domingo Soriano correu hestant en Caragoca los quales li heran deuidos por razón de un uiage que de mandamiento del dito senyor fizo por todos/ los lugares del condado deurgell enel regno daragón situados or caterse clamar las administraciones delas rentas delos ditos lugares por dar conto e razón de aquellas al dito senyor obispo e por informarlo quántas e quáles rentas eran enlos ditos lugares enel qual uiage estuuo el dito correu entre hyr estar e tornar XXX días..., fols. LIIIV-LIVr. (85 sueldos).

33

- 2 enero 1414. Item dio de mandamiento e hordenación del dito senyor obispo a Stheuan Caragocano portero dela casa del senyor rey los quales li heran deuidos por rasón de algunas missiones que fizo por las billas e lugares do fue como subdelegado del dito senyor obispo a prender e occupar los bienes delos rebelles..., fol. LIVr. (40 sueldos y 4 dineros jaqueses).

34

- 3 enero 1414. Item dio de mandamiento del dito senyor obispo a Héztor Capata scudero alguazir del gouernador daragón los quales el dito senyor obispo li mandó dar por las missiones que él hauía fetas con siete de cauallo en XII días que fue de mandamiento del dito senyor obispo al lugar de Pola por prender e occupar los exbagos de aquel amanos dela cort del senyor rey..., fol. LIVv. (3 florines).

- 17 febrero 1413. Item dio de mandamiento e hordenación del dito senyor obispo a mossén Remón de Mur cauallero consellero e bayle general del regno daragón los quales li heran deuidos porque aquellos él de mandamiento del dito senyor obispo e delos capitanes castellanos él hauían bistraydos asín en salarios de porteros de sobre junteros que fagan leuantar los bienes delos lugares que no se podían tener dallá el río de Ebro e enlas muntanyas de Jaqua o en salarios después e contra quel dito bayle tenía por los passos delas muntanyas de mandamiento delos ditos capitanes como la gent darmas delos yngleses se dezya que deuían entrar enel regno en fauor del comte durgell como el senyor rey era sobrel sitio de Balaguer..., fol. LXIIIr. (231 sueldos jaqueses y 90 florines de oro).

\section{6}

- 24 diciembre 1413. Item dio de mandamiento del dito senyor obispo a Bernat Plaza notario que aquellos hauían perdidos e bistraydos en carretas e en hombres que los acompanyauan como fueron dallá el río de Ebro el Johan de Pila e Pedro Ortiz de Zaualza por prender uillas e castiellos e 
otros bienes mobles e arendar aquellos que eran delos rebelles contra el senyor rey la guerra o rebellión del comte durgell..., fol. LXIVr. (36 sueldos jaqueses).

\section{7}

- 24 de diciembre 1413. Item dio de mandamiento e hordenación del dito senyor obispo a Bernat Plaza notario los quales li heran deuidos por razón de CXXIIII piecas de processo e cartas públicas quel como notario ha testificadas e actuadas en prender en tomar los bienes delos que han seydos rebelles al senyor rey ha manos dela cort del dito senyor por los comissarios hauientes poder adaquesto affin enla ciudat de Caragoca como de fuera enlos lugares de Quart Billa/ Nueua de Burgazut la billa Dalagón enlos lugares del río Dexalón del río de Borja e dallá el río de Ebro enlas billas de Tahust de Exea de un castiello de Sos e del lugar de Lexana e otros lugares dela montanya segunt que enel dito processo largament yes contenido..., fols. LXVIv-LXVIIr. (144 sueldos y 8 dineros jaqueses).

\section{e) Otros}

- 22 diciembre 1413. Item dio de mandamiento e hordenación del dito senyor obispo a Martín García portero de casa dela senyora reyna los quales el dito senyor le mandó dar yes a saber a una parte como fue a dalcanyz et a Montalbán por cobrar çiertas rentas reales que heran deuidas $V$ florines e aotro cabo como fue a Hoscha ensemble conel dito Francés Ferriol por cobrar çiertas quantías que li heran deuidas de las ditas rendas otros $\mathrm{V}$ florines e aotro cabo como fue ala billa dalcolea e aotros lugares del condado durgell por mandamiento del dito senyor obispo por recaudar e hauer gallinas capones e otra bolatería pora la fiesta dela coronación del senyor rey..., fol. LIIIv. (16 florines).

\section{9}

- 8 marzo 1413. Item dio a Bernat Plaza notario de mandamiento e hordenación del dito senyor obispo los quales li heran deuidos por salario de $\mathrm{V}$ días de aquellos XI días que vaquó en hyr conel dito Ffrancesch dela ciudat de Caragoca ala ciudat de Huescha que fue enel mes de deziembre más cerqua passado por cobrar e auer delas aljamas delos jodíos e moros dela dita ciudat las rendas reales que deuían de tiempo pasado al senyor rey..., fol. LIXv. (25 sueldos jaqueses). 
